\title{
Multiscale image-based modelling of damage and fracture in carbon fibre reinforced polymer composites
}

DOI:

10.1016/j.compscitech.2020.108243

\section{Document Version}

Accepted author manuscript

Link to publication record in Manchester Research Explorer

\section{Citation for published version (APA):}

Sencu, R. M., Zhang, J., Wang, Y., Withers, P., \& Soutis, C. (2020). Multiscale image-based modelling of damage and fracture in carbon fibre reinforced polymer composites. Composites Science and Technology.

https://doi.org/10.1016/j.compscitech.2020.108243

\section{Published in:}

Composites Science and Technology

\section{Citing this paper}

Please note that where the full-text provided on Manchester Research Explorer is the Author Accepted Manuscript or Proof version this may differ from the final Published version. If citing, it is advised that you check and use the publisher's definitive version.

\section{General rights}

Copyright and moral rights for the publications made accessible in the Research Explorer are retained by the authors and/or other copyright owners and it is a condition of accessing publications that users recognise and abide by the legal requirements associated with these rights.

\section{Takedown policy}

If you believe that this document breaches copyright please refer to the University of Manchester's Takedown Procedures [http://man.ac.uk/04Y6Bo] or contact uml.scholarlycommunications@manchester.ac.uk providing relevant details, so we can investigate your claim.

\section{OPEN ACCESS}




\title{
Multiscale image-based modelling of damage and fracture in
} carbon fibre reinforced polymer composites

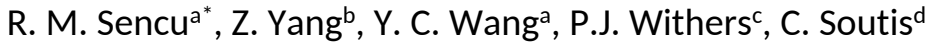 \\ [a] School of Mechanical, Aerospace and Civil Engineering, University of Manchester, M13 9PL, UK \\ [b] Centre for Low Impact Buildings, Faculty of Engineering and Computing, Coventry University, CV 5FB, UK \\ ${ }^{[c]}$ Henry Royce Institute, School of Materials, University of Manchester, M13 9PL, UK \\ [d] Aerospace Research Institute, University of Manchester, M13 9PL, UK
}

\begin{abstract}
This paper is the first to predict and then validate the overall tensile stress-strain curve, and the associated damage sequence comprising matrix cracking, interface debonding and fibre fracture against X-ray Computed Tomography (CT) observations for a multidirectional laminate. Until recently, numerical modelling of multi-directional multi-ply composites required idealised continuum mechanics models or idealised unit cell approaches (or homogenisation method) that cannot reliably capture property variations and the complex sequence of damage events that occur upon tensile loading.

Here, a multiscale image-based model is used to simulate stochastic crack growth in a double-notch $\left(-45^{\circ} / 90^{\circ} /+45^{\circ} / 0^{\circ} /-45^{\circ} / 90^{\circ} / 45^{\circ} / 0^{\circ}\right)_{s}$ carbon fibre reinforced polymer (CFRP) composite specimen subjected to tensile loading monitored by time-lapse X-ray CT. The data integration approach involves: (1) parallel simulations of meso-scale elements (MeEs) for each ply for which the orientation of the individual fibres has been extracted from an X-ray CT image, (2) local hierarchical coupling of the MeEs into a macro-scale mechanical model of the test piece, and (3) the use of a random variation in material properties where microstructural details are not revealed by the $\mathrm{X}$-ray $\mathrm{CT}$ characterisation method.

Cohesive interface elements (CIEs) are used at both scales to predict the accumulation of interface damage and crack growth. The fibre-level modelling captures the detailed damage sequence and crack morphology including fibre/matrix debonding, sliding, matrix cracking and fibre fracture events. The multiscale model is validated by comparison with the measured tensile loading curve and the damage evolution recorded by the X-ray CT.
\end{abstract}

Keywords: Stochastic fracture mechanics; synchrotron micro-tomography; hierarchical modelling; representative volume element (RVE); cohesive interface elements; crack propagation model. 


\section{Introduction}

It is common that due to the very large number of fibres commonly contained in carbon fibre reinforced polymer (CFRP) composites, numerical stress analyses normally neglect the individual fibres and assume homogeneous orthotropic material properties. In order to capture phenomena relating to fibre-fibre interactions and the fibre-matrix interfaces, existing multiscale finite element methods currently employ reduced-order models. In such calculations, models often make use of a simplified 'representative volume element' (RVE) [1] through which the whole composite structure is generated from a small repeating unit cell. Such models are typically unreliable, especially for composites that show localised and time-related damage growth, as recently pointed out in $[2,3]$. Closer examination has also shown that the 'representative volume element' assumption does not hold for inelastic case studies [4-7]. It is thus frequently preferred to employ local averaging techniques which reduces the accuracy of structural and local-to-global damage mechanics. This is also hindering the predictive capability of software packages, as well as limiting the extent to which modelling can be used to optimise new engineering designs for rapid prototyping and testing. As a result, the introduction of new composite systems can become prohibitively expensive to certify due to the reliance on extensive hierarchical structural testing schemes from test-piece to full-scale component.

Until now however, the deformation and damage mechanics modelling of continuous fibre reinforced materials have been studied predominantly using 2D methods such as: the statistical-RVE methodology [8], embedded cells [9], random tiles and meso-scale probabilistic transfer models [1012], neural-networks for training material damage behaviour with single or one-to-many finite element coupling strategies [13], concurrent adaptive and multi-level coupling strategies for brittle fibre materials and aluminium alloys $[14,15]$ and computational homogenisation with fracture energybased transfer models [16, 17].

Due to the wide range of scales and typically complex fibre specifications and fabric patterning architectures, additional numerical challenges have been encountered when performing 3D analyses. As a result, very few 3D studies have been carried out and then only for relatively simple fibre architectures, for example predicting the damage in unidirectional glass fibre composites where the material constants were directly computed from models or image-based homogenisations $[18,19]$. The modelling of polymer composites at the component scales has however significantly been based on the concept of reduced order microstructural models [6,20], while the fracture phenomena was captured using merged material plasticity and damage models [21-23]. This direction can be aligned with the new X-ray computed tomography (CT) technology and the information of such tests, which has been proven useful in providing the necessary 3D coordinates relating to the distribution and misalignment of fibres in long fibre composites [24]. Further studies have also shown that X-ray CT can deliver models for the identification of fibre-to-fibre contacts in disordered fibrous media [25, 26], and to identify indeed the complete trajectories of 1000's of fibres [27].

In addition, X-ray CT has been used to monitor damage evolution. For example, studies have addressed to the fatigue damage sequence around the crack-tip in a $\mathrm{Ti} / \mathrm{SiC}$ metal matrix composite $[28,29]$, for tracking damage accumulation and fatigue failure mechanisms in carbon/epoxy composites [30-32], and for assessing the effects of manufacturing defects and kink-bands on compressive failure [33, 34]. Furthermore, innovative time lapse X-ray CT testing has been combined with in-situ and ex-situ loading strategies to inform modelling approaches [32]. High resolution X-ray CT images have thus created an opportunity for new multiscale numerical modelling strategies, generating image-based finite element meshes at the fibre and ply levels that contain both straight and inclined fibre orientations $[35,36]$. 


\section{Motivation}

Our aim is to develop and validate a realistic multiscale model of a multi-ply laminate capable of capturing the key damage mechanisms and their sequence during tensile straining of a notched testpiece. Automated fibre segmentation is used to analyse X-ray CT images and to extract realistic fibre distributions characteristic of each of the $-45^{\circ}, 90^{\circ},+45^{\circ}$ and $0^{\circ}$ plies, making up the tensile gauge region of a CFRP sample. The fibre distributions are then integrated into a multiscale framework which, as illustrated in Fig. 1, comprises 2 scale levels. The meso-scale level where individual fibres are modelled is able to capture the detailed damage sequence including micro-cracking, debonding, sliding, fibre breaking and matrix cracking events. A macro-scale continuum model is used to describe the overall ply and test-piece architecture. For both models zero thickness cohesive elements are used. Randomised material properties are defined where microstructural details could not be obtained from the X-ray CT characterisation and meso-scale modelling methods. The predictions of the multiscale model are evaluated by comparison to the tensile loading curve for the test-piece as well as the damage measured by X-ray CT.

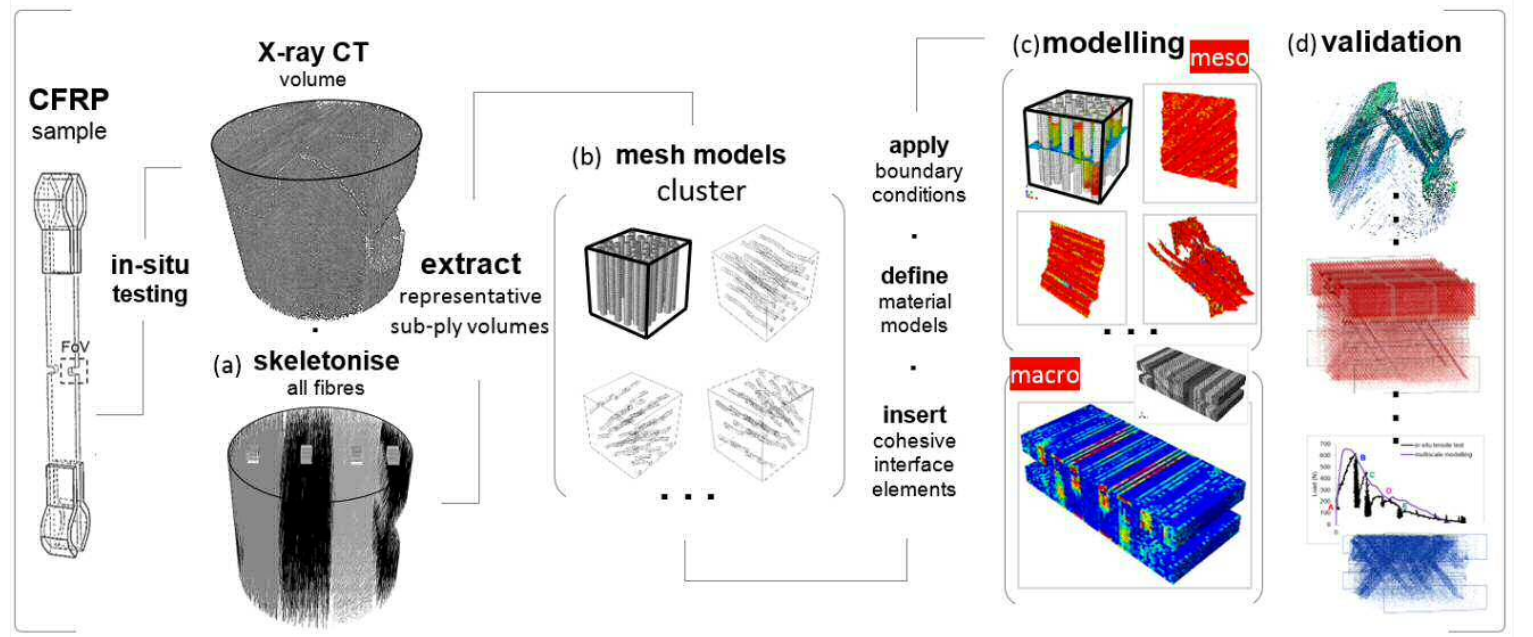

Fig. 1. Proposed hierarchical multiscale modelling scheme showing a) a skeleton image-based model of all reconstructed fibre centrelines, $b$ ) a representative meso-scale cluster of reduced order elements used to predict the properties and capture the damage mechanisms representative of the individual plies, $c$ ) the multi-scale modelling results of both meso and macro global models, and $d$ ) the validation of a composite test-piece.

Such multiscale methodologies using the cohesive zone modelling approach have been vastly used in the previous composite literature. Notably, the studies of Needleman on the cohesive energy based approach [4, 37, 38] , the work of Kanninen et al. [39, 40], the work of Costa et. al [41], they worked effectively for understanding damage at fibre and ply levels. The work by Song and Waas and other continuations of their work [42, 43], specifically for formulating cohesive models are still applicable to composites and were similarly based on the energy approach. The variational multiscale cohesive method (VMCM) introduced by RudraRaju et. al. [44, 45] is also perceived offering superior capabilities in terms of capturing discontinuities as reviewed by Oliver et al. [46].

Some of the advantages of a macro-scale continuum model for the numerical strategy are sometimes given by the capability of using an inner model which works based on the parallelisation concepts, while enabling as such to deploy a large number of micro-scale models. Such a strategy was previously used to inform the material constitutive definitions in [47], where an adaptive energy based criteria have been established using the cohesive zero thickness elements for 2D length scales individually, and were linked by an overlapping grid multiscale coupling method.

In the present study, the intention is to build upon the previous knowledge using the orientation of the individual fibres as revealed by the X-ray CT technology. These have been previously covered in 
[36]. Because, the coupling to macro-scale mechanical model of the test piece currently requires the use of a random variation in material properties, we employ such numbers, where microstructural details are not revealed by the X-ray CT characterisation method.

The cohesive interface elements (CIEs) are thus implemented similarly to the 2D case study for both the material length scales in $3 \mathrm{D}$ in this paper. The aim is to predict the accumulation of interface damage and crack growth for the upper one. The multiscale model is validated by comparison with the measured tensile loading curve and the damage evolution recorded by the $\mathrm{X}$ ray $\mathrm{CT}$.

\section{Experimental details}

\subsection{Material}

The material investigated is a carbon/ epoxy multi-directional laminate that contains 16 plies. Each ply was manufactured to have a target fibre content of about 50 vol\% of $5.2 \mu \mathrm{m}$ carbon fibres in diameter. The stacking sequence is $\left(-45 \% 90 \%+45 \% 0 \%-45 \% 90 \%+45 \% 0^{\circ}\right) \mathrm{s}$, where the thickness of each ply after manufacturing was approximately $250 \mu \mathrm{m}$. The nominal thickness of the laminate is 4 $\mathrm{mm}$.

Although in practice some variation in diameter and ovality undoubtedly occurs as a result of the production of carbon fibres, this has not been incorporated into our current modelling strategy. This is partly due to limitations in term of contrast and spatial resolution of the X-ray computed tomography (CT), partly because their effect is likely to be small and partly due to the further numerical challenges of mapping such high level details and dealing with them in rather large numerical dataset and modelling instances. Consequently, an average value of $5.2 \mu \mathrm{m}$ carbon fibres in diameter was used based on multiple cut inspections. These inspections were conducted by optical means during the segmentation work in [36]. The generation of the FE models and the optical image quantification of certain parameters have been also discussed in greater details as part of a Ph.D. study in [48].

\subsection{Tensile test-piece and loading rig}

A $4 \mathrm{~mm}$ thick double-notched composite test-piece was cut using thin water blade sawing and end tabs applied as seen in Fig. 2-a. The specimen surface notches shown in Fig. 2-c were introduced across the $1.80 \mathrm{~mm}$ specimen width using a $300 \mu \mathrm{m}$ thick carbide blade. The steel end-tabs were glued to the specimen using a bi-component epoxy adhesive so that it could be loaded in-situ upon the stage of the synchrotron beamline as shown in Fig. 2-a.

This non-typical test geometry with the notches in the thickness direction of the laminate was adopted for practical reasons. The sample design helps to concentrate the damage in a localised area which can be imaged non-destructively by X-ray CT at a resolution sufficient to the individual carbon fibres. On the other hand, the volume seems to be sufficient to contain the essential multiple laminate structures which enables us both to set up a geometrically faithful model and assess the damage that is generated during tensile straining in a sample large enough to reflect composite behaviour. In other words, this balance between high spatial resolution to image individual fibres and damage and sufficient composite volume to be realistic from an engineering viewpoint is a key issue for the X-ray imaging of composite behaviour [32]. Therefore, the concentration of the damage in a localised area which can be imaged non-destructively within the field of view of high resolution X-ray CT is to better understand how these defects form and propagate across the length scales. Once this understanding has been gained the modelling can be applied to other, less idealized, geometries.

The in-situ loading rig is shown in Fig. 2- $a, b$. It features a dismountable X-ray transparent loading tube, a two-way linear actuator, a load cell and a motion controller. The selected specimen geometry and dimensions are constrained by the X-ray CT field of view. As shown in Fig. $2 \mathrm{c}$ and d, the geometry of the notch runs across the full sample width of $1.80 \mathrm{~mm}$. The resulting radius of the in-depth cutting part was given by the carbide blade. This is believed to be fairly constant after analysing some of the 
X-ray CT datasets and large resolution optical images in Fig. 2-d, and can be thus assumed equal to $300 \mu \mathrm{m}$ as given by half length of the $600 \mu \mathrm{m}$ carbide blade thickness.

In future it would be useful to quantify more precisely the exact geometry of the notches. Although this is possible by either 3D or 2D methods such as scanning by image stitching or extremely accurate machining at microscale level and subsequent 2D optical analyses, it was not done in this case.
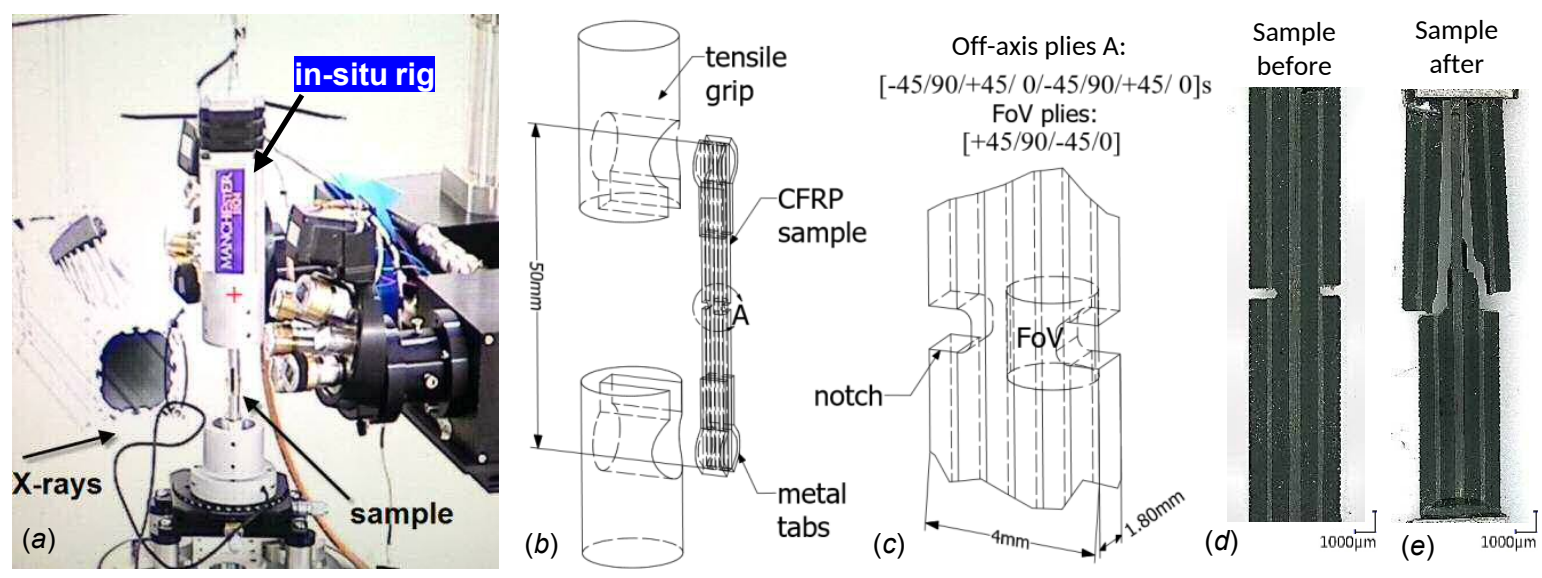

Fig. 2. a) In-situ double notch tensile test using a new loading rig conducted on the Diamond-Manchester X-ray CT branchline I13-2 at the Diamond Light Source, b) schematic of the samples and grips, c) magnified image of the notch region and single field of view (FOV) of the X-ray $\mathrm{CT}$, d) stitched optical image of typical samples before and d) stitched optical image of sample after the $\mathrm{X}$-ray $\mathrm{CT}$ in-situ test.

Fig. 3 shows the main details of the mechanical loading rig, its instrumentation and a schematic control diagram. The assembly comprises of a linear actuator, a fast changing sample tube, a lower housing block, an upper housing block and a stepper motor control module. The acquisition of any of the tensile and compression forces is conducted via a compression button load cell. The load cell is fitted in the lower housing block. The initial rig could do either tensile or compression tests, but could not alternate dynamically between the two options due to some fixture changes to allow the outer tube to slide or remain static. As such, when tests were conducted for direct tension the outer tube transferred the load via a coin bearing equal to the outer diameter and fitted on top of the compression load cell; and when compression tests were conducted, the outer tube was used to take the reaction of the total force undertaking up to the equivalent tensile capacity of the testpiece. The displacement measurements were recorded with a linear vertical displacement transducer (LVDT) of relatively small stroke up to $10 \mathrm{~mm}$. The LVDT was attached on the side of the slotted brackets (note - the LVDT is only shown here in the control diagram in Fig. 3-b and was attached via a bracket on the side of the slotted plate Fig. 3-a ). 

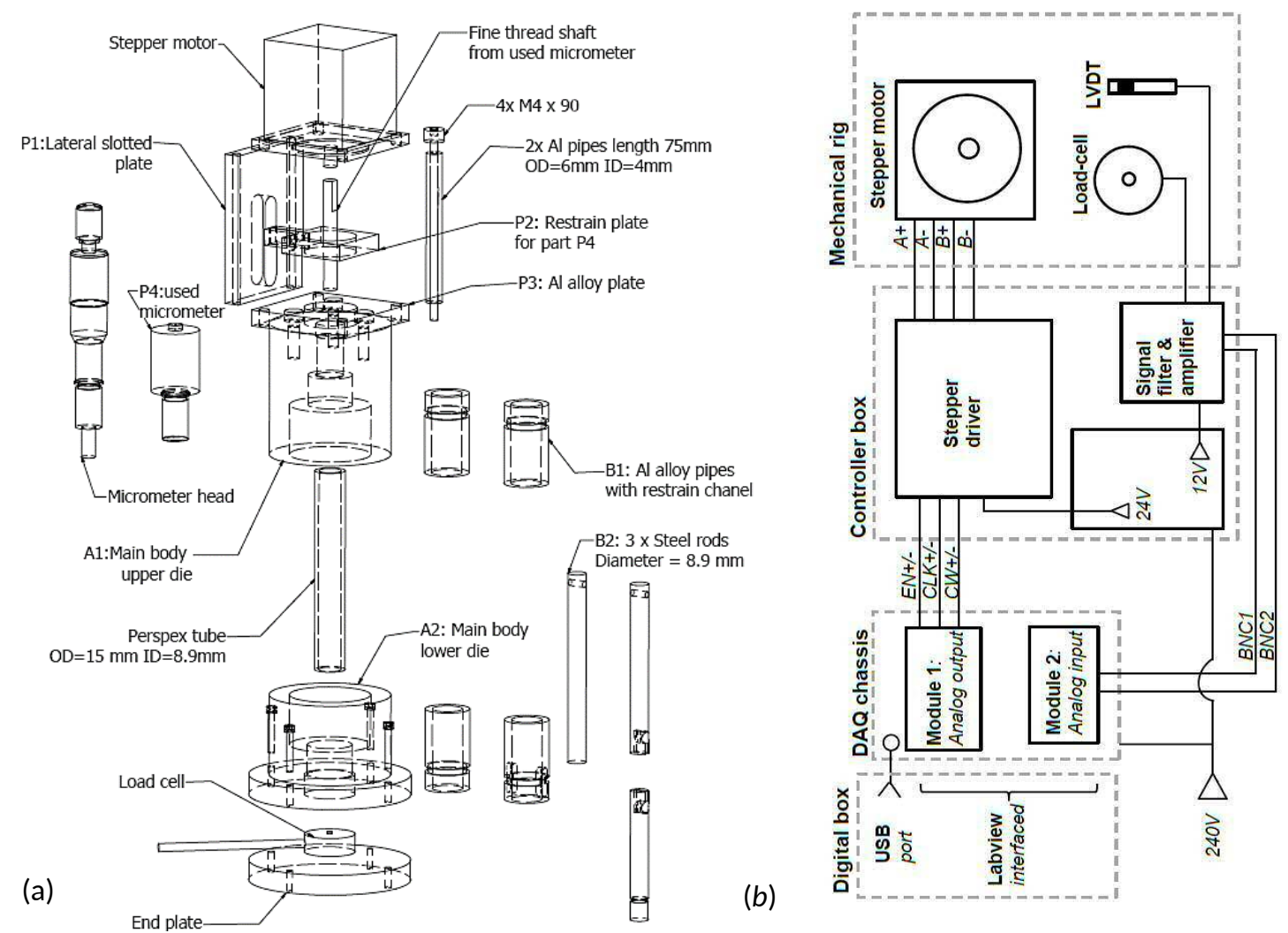

Fig. 3: Micro-step controlled X-ray CT in-situ loading rig a) the mechanical rig and b) its diagram and control details. Note: this rig was design for specific features towards: i) fast sample changing, 2) improved positioning \& calibration capabilities, iii) allowance for any of the tension or compression loading modes and iv) provision of micro-controllable loading programmes.

\subsection{In-situ test}

The test-piece was loaded step-wise on the Diamond-Manchester Imaging Branchline I13-2 at the Diamond Light Source in the United Kingdom. The uniaxial tensile test curve for the investigated composite is shown in Fig. 4. The displacement is measured by the cross head movement at the upper grip end by means of a laterally attached LVDT.

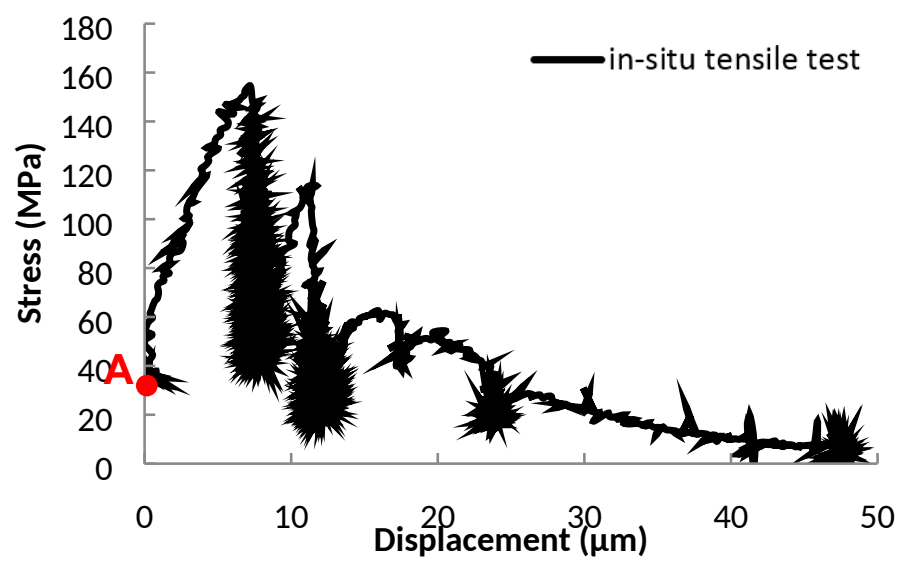

Fig. 4. Incremental uniaxial tensile test curve of a double notch composite specimen undertaken at the Diamond Light Source: at each dwell a CT scan was recorded after which the straining was resumed. Some load was maintained at each unload stage in order to keep the sample firmly located within the rig. 
The overall behaviour starts from a preloaded stress state of around 30MPa and exhibits some stress relaxations that could be related to a combination of visco-elastic relaxation and rig tightening reasons. The initial load was used to be able to keep sample firmly in place while scanning in the rotating tomography standard environment, although in the future this needs to be minimised or avoided completely when possible.

\subsection{X-ray CT imaging}

The synchrotron X-ray computed tomograms were reconstructed from their projections (radiographs) using a filtered back projection approach [49]. Each tomogram consists of a stack of 2160 slices each comprising $2560 \times 2560$ pixels. The effective pixel size at $20 X$ optical magnification was approximately $330 \mathrm{~nm} /$ pixel. This corresponds to a volume approximately $712 \mu \mathrm{m}$ in height by $840 \mu \mathrm{m}$ in diameter (see Fig. 5-a). This pre-test image volume has been used previously as the geometric basis for FE modelling in [36]. The X-ray CT captured volume contains a total of about 11950 individual fibres with lengths ranging from $170 \mu \mathrm{m}$ to $1100 \mu \mathrm{m}$ within the field of view.

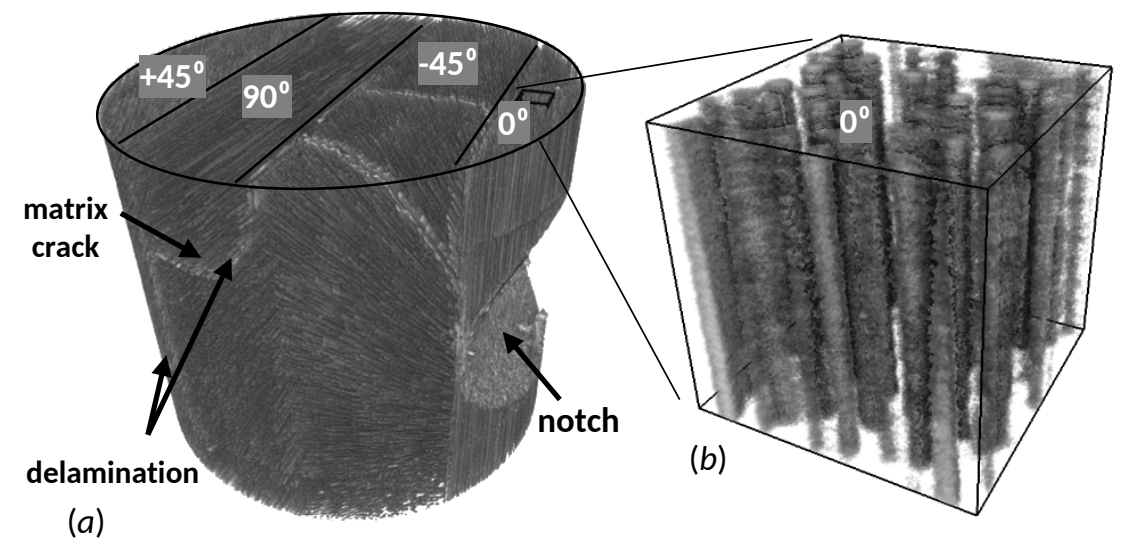

Fig. 5. X-ray CT volume renders of: (a) the field of view (FoV) from the double notched sample (which includes one of the notches) under a uniaxial tensile load of $20 \mathrm{MPa}$ (first load step) where each ply thickness is $250 \mu \mathrm{m}$ and b) a magnified region of interest (Rol) at the ply level (the matrix is rendered transparent), both prepared using the volrenGreen render tool in Avizo 8.0 software package [50].

\section{Modelling methodology}

\subsection{Numerical approach}

The complete numerical approach contains 3 main steps using the X-ray CT image-based modelling strategy as its basis; 1 ) image-based modelling to form meso-scale models, 2) hierarchical coupling of the meso-scale models to form a macro-scale model, 3) final validation of the simulation with the tensile test results.

In order to avoid numerical difficulties associated with the actual specimen setup, the simulation involved the following simplifications:

the two metal end tabs and tensile grips presented in the in-situ test rig were not modelled to reduce the computational and concurrent coupling challenges,

modelling was only focused on a local deformable region as a smaller part of the tensile testpiece, while the remaining domain was not included in the simulation,

the fibre to fibre strength variation has not been captured here because of lack of strength on Weibull modulus data for the fibre of interest. This would be worthwhile in future models. 
the material properties at the interface of each of the different plies were assumed to be weaker by $10 \%$ than the epoxy matrix and interfaces. Other variability to account for fibre bridging effects of the different inter-ply regions is not considered. Some CFRP laminates are material designed with inter-ply resin rich areas exploiting cross-bridging by chopped fibres or nanocoating and resin functionalising technologies that can further enhance shear and normal strengths opposite to this study. Our assumption has been chosen to identify a lower bound via the $10 \%$ reduction of strength.

\subsection{Image-based modelling at meso-scale}

In total, 8 image based meso-scale models have been constructed for the 4 complete plies in the Xray CT field of view (Fig. 6). Each model size was $50 \times 50 \times 50 \mu \mathrm{m}^{3}$ and they were extracted from different regions of interest (Rol) in such a way that they preserve the directions of the global system of coordinates. To obtain a higher accuracy of the modelling results and to allow statistical comparisons between the sets 2 volumes extracted for each of the different ply angles (see Table 2).

To build each model, the individual fibres have been tracked using the automated approach described by [36]. These have then been used to generate micro-scale finite element models. To counter numerical and data storage limitations, only the 8 image-based meshes are used in this study. These are the 3D equivalents of the so-called meso-scale elements (MeEs) used previously within a 2D multiscale stochastic fracture modelling framework [47, 51].
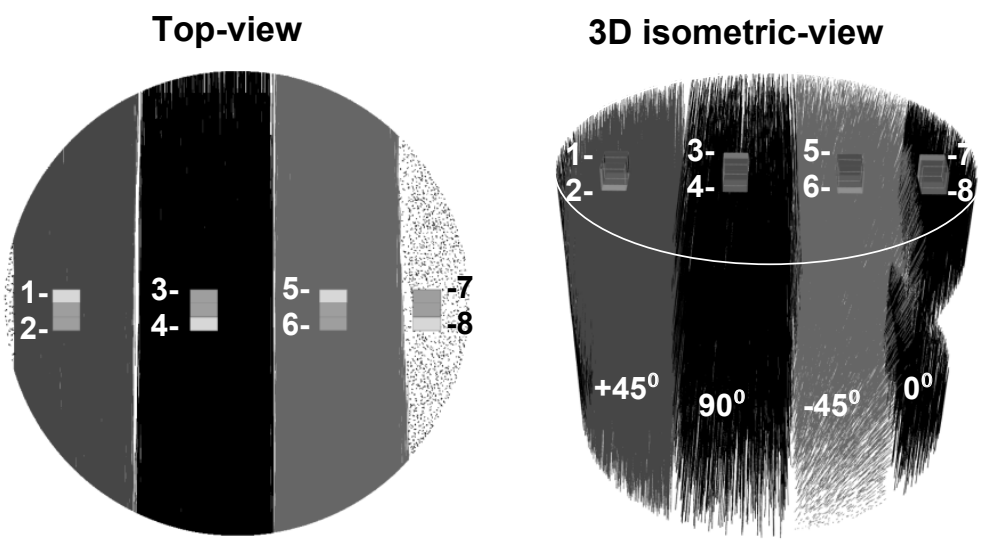

Fig. 6. A representation of the individual extracted fibre trajectories extracted from the X-ray CT FoV of the 4 plies $\left(\left[+45^{\circ} / 90^{\circ} / 45^{\circ} / 0^{\circ}\right]\right)$ with eight $50 \mu \mathrm{m}$ cuboids (regions of interest) arranged in four overlapping pairs (one pair for each ply). The white ellipse in the isometric view has been added for clarity. 

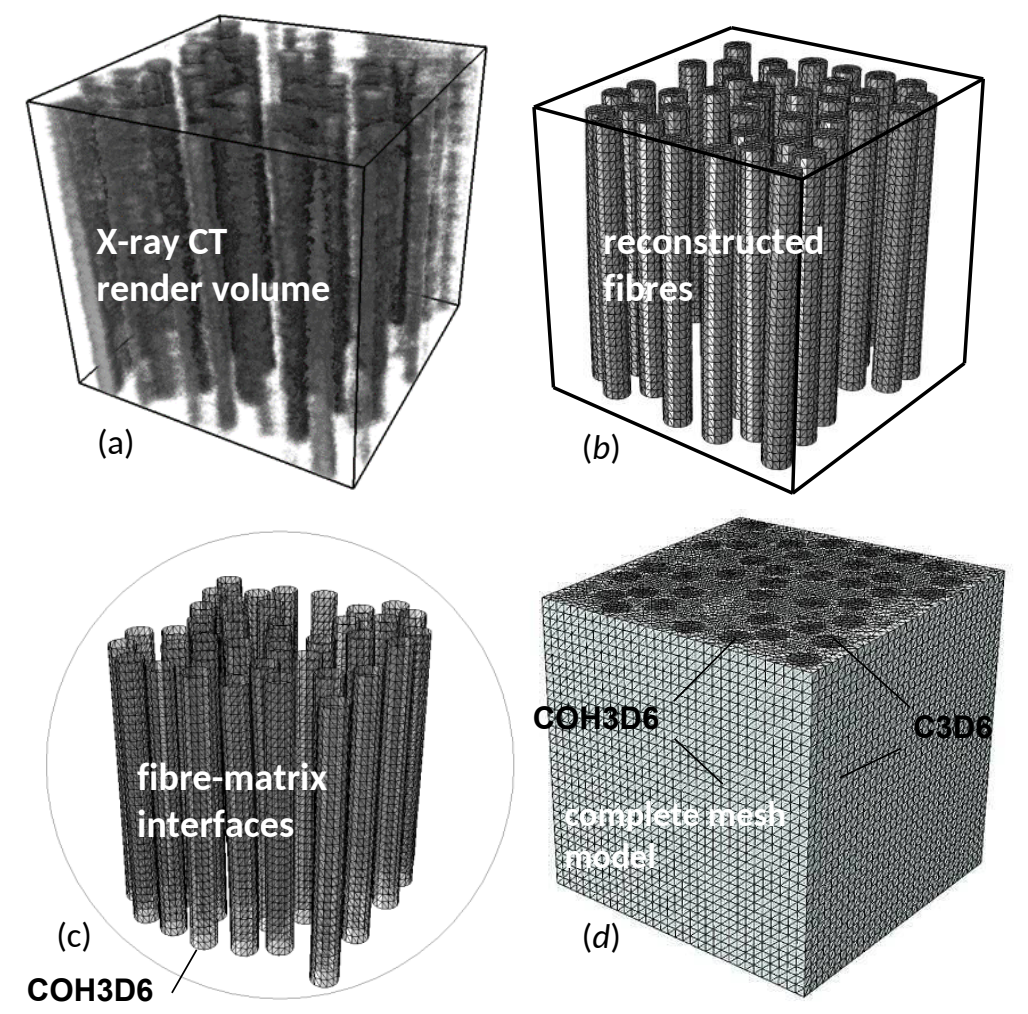

Fig. 7. a) An X-ray CT Rol image of a meso-scale volume (no. 8) for the $0^{\circ}$ ply in Fig. 6 and b-d) the corresponding reconstructed image-based mesh model (MeE-8 in Table 2).

In order to capture the micro-crack propagation and fracture process, each meso-scale model required a fine mesh size. This size was also found favourable to avoid FE instabilities and numerical sensitivities. To this end an element size of $1 \mu \mathrm{m}$ is used in the reconstruction, assuming a constant fibre diameter of $5.2 \mu \mathrm{m}$.

The mesh comprises two finite element types namely C3D4 and COH3D6; both available in ABAQUS. Linear elasticity material models are used to define all material phases at meso-scale [52]. The fracture process is modelled in the three constituent phases (fibres, matrix and interfaces) using meso-scale cohesive interface elements (meso-CIEs) that are pre-inserted accordingly. The crack growth is allowed to progress through any of the three element phases without restriction.

Crack onset and propagation processes can be determined using two criteria, namely the maximum stress failure criterion and the quadratic traction-interaction criterion (QUADS) the latter being particularly useful in modelling mixed-mode behaviours. Due to better numerical distortion control in complicated 3D fracture problems, the QUADS criterion was used in this study. The softening (after element crack initiation) follows the energy-based approach ( ${ }^{*}$ ENERGY) and the cohesive element control in mixed-mode behaviour was implemented based on the second order power-law (POWER) available in ABAQUS [52].

The solid and cohesive interface elements are distributed in a uniform manner without localised mesh refinements. The insertion runtime shown in Table 2 is the FE pre-processing of the reconstructed mesh for embedding it with cohesive interface elements. The interface elements are needed to simulate the cracks discretely. Thus, within all the image-based simulations, the explicit dynamic solver is used along with its displacement control feature. The meso-scale material modelling parameters and some of the manufacturer specifications are given in Table 1. It should be noted that there is a slight discrepancy between the manufacturing target fibre volume fractions in Table 1 and 
the measured values after segmentation shown in Table 2. Two possible reasons are 1) the size of partitioned cuboids being smaller and coordinate dependent as presented in Table 2 and 2) the further misidentification and tracking of some of the fibres during the imaging and reconstruction processes.

Table 1

Material specifications and properties for meso-scale fracture modelling.

\begin{tabular}{|l|c|c|c|c|}
\hline \multicolumn{1}{|c|}{ Parameters } & SI Units & Carbon fibre & Epoxy resin & Interface \\
& & & & \\
\hline Elastic modulus (chord 6k-10k) & $\mathrm{GPa}$ & 276 & 3.35 & 3.35 \\
\hline Tensile strength $\mathrm{t}_{\mathrm{n}}=\mathrm{t}_{\mathrm{s}}=\mathrm{t}_{\mathrm{t}}(6 \mathrm{k})$ & $\mathrm{MPa}$ & 5515 & 50 & 25 \\
\hline Poisson's ratio $\mathrm{v}$ & - & 0.22 & 0.35 & 0.37 \\
\hline Fracture energy $\mathrm{G}_{11}=\mathrm{G}_{22}=\mathrm{G}_{33}$ & $\mathrm{~J} / \mathrm{mm}^{2}$ & 0.287 & $50 \mathrm{e}-03$ & $25 \mathrm{e}-03$ \\
\hline Density & $\mathrm{kg} / \mathrm{m}^{3}$ & & 1500 & \\
\hline Volume fraction & $\%$ & 50 & 50 & - \\
\hline Fibre diameter & $\mathrm{mm}$ & $5.2 \mathrm{e}-03$ & - & - \\
\hline Ultimate elongation at failure & $\%$ & 1.9 & 2 & 2 \\
\hline Twist & - & never twisted & - & - \\
\hline
\end{tabular}

Note: The Poisson's ratios are assumed according to some of similar manufacturer specifications. The subscripts for fracture energy is to define fibre direction and transverse, where 11 refers to in line with fibre longitudinal centerlines. 22 and 33 are the 2 other transverse directions ortho-normal to 11 centrelines.

The boundary conditions at the meso-scale are illustrated in Fig. 8. Three loading types are considered:

-Type A: uniaxial (any direction $\mathrm{x}, \mathrm{y}, \mathrm{z}$ ) tensile with two restrained surface sides and planar displacement loading.

-Type B: cube shearing (any direction $x, y, z$ ) spaced at one-third the size of the model.

-Type C: uniaxial tensile (any direction $\mathrm{x}, \mathrm{y}, \mathrm{z}$ ) with single restrained surface side.

The rationale behind choosing these three loading and boundary constraint conditions is to capture the most common types of micro-mechanical failures. The basis of using similar 2D multiscale modelling loading conditions was previously validated in [47].

(a) Type-A

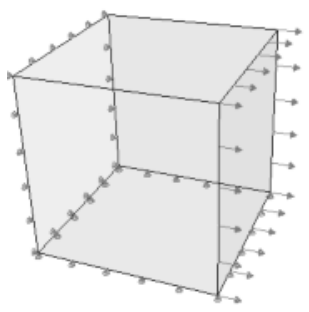

(b) Type-B

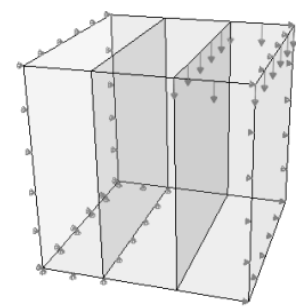

(c) Type-C

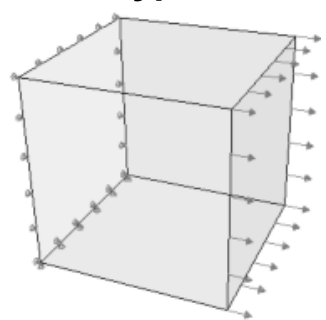

Fig. 8. Boundary conditions considered at the meso-scale: $a$ ) uniaxial tensile with restrained sides, $b$ ) shearing using one-third edge size bandwidth, and c) uniaxial tensile with single restrained side.

The set of 3 boundary conditions are considered for all orientations of the local Cartesian axes. This approach gives a minimum of 9 model simulations per each fibre-level meso-scale volume that is extracted. However, some of the boundary condition simulations become redundant at the expense of parallelization due to the bottom-up hierarchical modelling approach that is followed here. This computational expense is because, not only that some modes are roughly giving the same results, but localisation of damage typically aligns with a top-down streamline that won't activate the whole material volume, and thus some parts will only suffer less deformations or no deformations in non- 
principal directions. Due to this being a first-time comparison, the modelling is performed using the same material and geometry model for all the boundary conditions. Responses are then used to define the macro-scale model presented below.

It is hypothesised that Type A should be recommended for small size volume cuboids, particularly where there is less potential of shear faults associated with longer crack surfaces and big fracture propagations. Alternatively, Type $C$ should be preferably used where volume images become larger, but not hitting a deformability incompatible threshold, as this could cause errors on the macro-scale model arising from a disparity of the partitioned volumes. Further sensitivity studies are merited.

Table 2

Image-based models extracted for the overlapping Rol shown in Fig. 6.

\begin{tabular}{|c|c|c|c|c|c|c|c|c|c|}
\hline \multirow[b]{2}{*}{$\begin{array}{l}\text { Model } \\
\text { ref. }\end{array}$} & \multirow[b]{2}{*}{$\begin{array}{c}\text { Ply } \\
\text { angle }\end{array}$} & \multirow[b]{2}{*}{$\begin{array}{c}\text { Fibre } \\
\text { volume } \\
\text { fraction }\end{array}$} & \multicolumn{7}{|c|}{ Mesh model information (number of elements) } \\
\hline & & & $\begin{array}{l}\text { Fibre } \\
\text { C3D4 }\end{array}$ & $\begin{array}{c}\text { Fibre CIEs } \\
\text { COH3D6 }\end{array}$ & $\begin{array}{l}\text { Matrix } \\
\text { C3D4 }\end{array}$ & $\begin{array}{c}\text { Matrix CIEs } \\
\text { COH3D6 }\end{array}$ & $\begin{array}{c}\text { Interface CIEs } \\
\text { COH3D6 }\end{array}$ & Total & $\begin{array}{l}\text { Insertion } \\
\text { runtime } \\
\text { (s) }\end{array}$ \\
\hline MeE-1 & $+45^{\circ}$ & $25 \%$ & 91314 & 166418 & 264008 & 508469 & 29839 & 1060048 & 647140 \\
\hline MeE-2 & $+45^{\circ}$ & $20 \%$ & 69727 & 126775 & 267230 & 518523 & 22834 & 1005089 & 548132 \\
\hline MeE-3 & $90^{\circ}$ & $15 \%$ & 50871 & 92782 & 270852 & 527530 & 16629 & 958664 & 357343 \\
\hline MeE-4 & $90^{\circ}$ & $15 \%$ & 50347 & 91730 & 272222 & 530362 & 16631 & 961292 & 566716 \\
\hline MeE-5 & $-45^{\circ}$ & $38 \%$ & 139395 & 254198 & 249367 & 470815 & 45042 & 1158817 & 792675 \\
\hline MeE-6 & $-45^{\circ}$ & $37 \%$ & 141152 & 257280 & 247583 & 467455 & 45759 & 1159229 & 803531 \\
\hline MeE-7 & $0^{\circ}$ & $34 \%$ & 122823 & 223587 & 271143 & 515826 & 40402 & 1173781 & 525211 \\
\hline MeE-8 & $0^{\circ}$ & $31 \%$ & 110360 & 201310 & 273015 & 523401 & 36028 & 1144114 & 563613 \\
\hline
\end{tabular}

\subsection{Macro-scale modelling}

Here the macro-scale mesh is first generated using an in-house Python script that uses the ABAQUS/ CAE libraries [53]. To allow a more realistic scale transfer, the macro-scale model includes special mesh elements discussed below.

The model uses a structured mesh that contains interfaces aligned along the most probable crack surfaces. The interfaces were based on the ply sequence of the composite. The anticipated cracks at the macro-scale can also be thought about as being merged micro crack surfaces. Thus, the merged cracks include: the matrix cracking, fibre bundle breaking intersecting the transverse matrix cracking, and failure of resin-rich regions. The macro-scale crack surfaces are summarised in Table 4.

It was assumed that the resin-rich type of failure also included non-planar type of delamination cracks, so that it could be extended to short distances from the inter layer surface regions. Because the mesh model contains strategically pre-inserted cohesive interface elements (referred as macro-CIEs), it is possible that the locations of the cracking mechanisms are not quite right which may affect the micro-damage processes and their responses on the global scale model. However, the macro-linked feature and the higher resolution image-based simulations, ensure a reasonably good approximation.

The model used for the macro-scale modelling comprises a mixture of solid elements (type C3D6) and two types of cohesive interface elements (COH3D6 and COH3D8). These elements are available in ABAQUS and can be grouped in a single material model to represent the oriented multidirectional ply stacking of the case study.

The use of a structured mesh at global and component scales has two main advantages, namely: (1) easy FE post-processing due to visualisation of the entire detailed crack surfaces per separate entities, and (2) better numerical controls within the material sub-routines. In this particular model, the latter advantage was essential to allow setting the orientation and cohesive sub-routines encountered in the study. 


\subsection{Macro-scale material definition}

The solid elements are assigned orthotropic material properties. The properties are obtained from the meso-scale (MeE) modelling and were found to simulate the complicated multidirectional response of CFRPs. The ply orientations are established using the *ORIENT subroutine available in ABAQUS. The constitutive formulation of these elements is linked to the non-linear responses of the MeE simulations above, and further generated responses.

The material properties that were generated assuming a random variation of about $10 \%$ as discussed above. Although, the application of a random variation holds no exact continuity, the random material choice was used as alternative to the solution of the complete computational domain which was more computationally expensive.

The principles of hierarchical multiscale modelling have been applied in order to fulfil the requirements of scale transfer. First, the elastic part of the stress-displacement curves is converted into stress-strain to obtain the constitutive elastic material model. The collective elastic stress-strain relationships are used to compose an orthotropic 3D elasticity tensor that combines the results from the different MeE boundary simulations. The 3D elasticity tensor is then linked to the solid elements contained in the global model.

The inelastic part (non-linear curve before rapid loss of load) located between the upper linearelastic point and the maximum stress point, is then used in the scale transfer as a 'pseudoorthotropic' plasticity input. This pseudo-orthotropic plasticity model is simply taken from the major boundary conditions response in this study. For example, the tensile boundary conditions along the MeE fibre direction. In order to ensure numerical convergence and avoid solid element distortions, the plasticity definition curve continues after the maximum stress point. For this reason, the curves are pre-simulated and then input in the macro-scale model.

To avoid convergence problems in ABAQUS, the continuation is done in a ramp-like manner, taking the local slope of the plasticity curve and an infinitely large strain step. Typically, when the non-linear model with monotonically increasing plasticity is triggered in local areas, no dissipative competition occurs between the plasticity within the 'bulk' solid elements versus the cohesive interface elements that define the crack opening behaviour at the global scale. This ensures that damage accumulates within the solid elements and cracks propagate via the activation of cohesive elements which are then defined by a fixed damage initiation criterion, such as the QUADS or MAXS criteria in ABAQUS. This also means that the cohesive crack initiation stress at the interfaces can be kept at approximately the same initiation value upon local material unloading, being forced by the neighbouring 'pseudo-plasticity' model attached to all solid elements contained in the global analysis.

After the initiation of a first crack, the fracture process goes into a 'softening' process. This process must typically be defined by an evolution criterion and it was estimated based on the principle of conservation of energy [47]. Thus, the equivalent of total fracture energy released by the corresponding MeE simulation is used at macro-scale. A more accurate alternative softening input can be defined using the tabular form. Instead, when the energy release model is used, nonlinearity of the softening part is controlled by a power-law that was previously tested in $2 \mathrm{D}[47]$. When the power law is employed, because the sequence of meso-scale damage is collectively inserted within the anisotropic macro-scale models, they affect the overall nonlinear behaviour. Such detailed damage sequences are extremely difficult to capture accurately in quasi-brittle behaviour due to the potentially uneven triggering and nucleation of cracks. For simplicity, the total energy released in the meso-scale modelling in this paper was first calculated and scaled accordingly to fit the $2^{\text {nd }}$ order power-law. The conversion step ensured a moderately realistic fracture mechanism across the scales.

Each ply contains a unique set of solid elements type C3D6. Because failure surfaces of the MeEs are approximated here by the integration of reduced order elements, the closest position of the macroCIEs to the simulated MeEs are assumed in the process of local-to-global mapping. In this process, all 
the obtained failure modes are mapped to the information of a closest corresponding macroscale cohesive interface element. Furthermore, the ply-to-ply delamination was only modelled using a single set of macro-cohesive elements. Although in principle many different responses could be linked to the resin-rich layers, thus simulating the bridging effects of different types of bi-layer orientations such as $0^{\circ}$ to $90^{\circ}$ plies and $+/-45^{\circ}$ to $90^{\circ}$ or $+/-45^{\circ}$ to $0^{\circ}$ plies, this was not further investigated in this paper.

Because the hierarchical multiscale modelling approach undertaken here neglects any topdown multiaxial stress states, this model further has to assume that any realistic full field stresses and their dynamic effects on the boundaries do not influence the overall global behaviours. These are important however in practice and should be included when simulating all the meso-scale volume elements in one complete laminate assembly model, especially for their complete validation purposes. So far, such numerical approaches have been conducted in relation to previous 2D investigations in $[47,51]$.

Table 3

Coupling information of macro- element sets contained in different fibre orientation plies.

\begin{tabular}{|c|c|c|c|}
\hline $\begin{array}{l}\text { Modelled } \\
\text { region }\end{array}$ & $\begin{array}{l}\text { Links of macro-CIE orientation sets } \\
\text { to MeE responses }\end{array}$ & Element types & $\begin{array}{l}\text { Number of } \\
\text { instances }\end{array}$ \\
\hline $0^{\circ}$ plies & $\begin{array}{l}\text { Coh0 }: M, \text { Coh90 } \\
\text { Coh }+45^{\circ}: \mathrm{O}, \text { Coh- } 45^{\circ}: \mathrm{O}, \mathrm{S}: \mathrm{EP}\end{array}$ & $\begin{array}{l}\text { COH3D6, COH3D8, } \\
\text { C3D6 }\end{array}$ & 4 \\
\hline $90^{\circ}$ plies & $\begin{array}{l}\text { Coh0 }: F, \text { Coh } 90^{\circ}: \mathrm{M}, \\
\text { Coh }+45^{\circ}: \mathrm{O}, \text { Coh- } 45^{\circ}: \mathrm{O}, \mathrm{S}: \mathrm{EP}\end{array}$ & $\begin{array}{l}\text { COH3D6, } \mathrm{COH} 3 \mathrm{D} 8, \\
\text { C3D6 }\end{array}$ & 4 \\
\hline$-45^{\circ}$ plies & $\begin{array}{l}\text { Coh0 }: \mathrm{T}, \text { Coh } 90^{\circ}: \mathrm{O} \\
\text { Coh }+45^{\circ}: \mathrm{F}, \text { Coh- } 45^{\circ}: \mathrm{M}, \mathrm{S}: \mathrm{EP}\end{array}$ & $\begin{array}{l}\text { COH3D6, COH3D8, } \\
\text { C3D6 }\end{array}$ & 4 \\
\hline$+45^{\circ}$ plies & $\begin{array}{l}\text { Coh0 }: 0, \text { Coh } 90^{\circ}: \mathrm{T} \\
\text { Coh+45:M, Coh- } 45^{\circ}: \mathrm{F}, \mathrm{S}: \mathrm{EP}\end{array}$ & $\begin{array}{l}\text { COH3D6, COH3D8, } \\
\text { C3D6 }\end{array}$ & 4 \\
\hline $\begin{array}{l}\text { Resin-rich } \\
\text { interfaces }\end{array}$ & $\mathrm{CohO}^{\circ}: \mathrm{RO}$ Coh0 $0^{\circ} \mathrm{RT}$ (3D orthotropic) & $\mathrm{COH} 3 \mathrm{D} 6$ & 15 \\
\hline
\end{tabular}


Meso-scale information and global multiscale modelling using ABAQUS.

\begin{tabular}{|c|c|c|c|}
\hline $\begin{array}{l}\text { Boundary type/ Failure mode } \\
\text { at meso-scale }\end{array}$ & $\begin{array}{l}\text { Macro-scale } \\
\text { element types }\end{array}$ & $\begin{array}{l}\text { Anisotropy } \\
\text { considerations } \\
\text { at macro-scale }\end{array}$ & $\begin{array}{l}\text { FE sub-routines for initiation/ } \\
\text { propagation / mixed modes } \\
\text { control/ orientation }\end{array}$ \\
\hline $\begin{array}{l}\text { Type-A transverse to fibres/Matrix } \\
\text { cracking with 3D decohesion (M) }\end{array}$ & $\begin{array}{l}\text { Cohesive: } \mathrm{COH} 3 \mathrm{D} 6, \\
\text { COH3D8 }\end{array}$ & 3D orthotropic & $\begin{array}{l}\text { QUADS, ENERGY, BK or power } \\
\text { law for mixed modes }\end{array}$ \\
\hline $\begin{array}{l}\text { Type-A along fibres/Matrix cracking with } \\
\text { fibre bundle breaks (F) }\end{array}$ & Cohesive: $\mathrm{COH} 3 \mathrm{D} 8$ & 3D orthotropic & $\begin{array}{l}\text { QUADS, ENERGY, BK or power } \\
\text { law for mixed modes }\end{array}$ \\
\hline $\begin{array}{l}\text { Type-A transverse to fibres/Transverse } \\
\text { matrix cracking (T) (inclined fibre } \\
\text { orientations at }+45^{\circ} /-45^{\circ} \text { ) }\end{array}$ & Cohesive: COH3D8 & 3D orthotropic & $\begin{array}{l}\text { QUADS, ENERGY, BK or power } \\
\text { law for mixed modes }\end{array}$ \\
\hline $\begin{array}{l}\text { Type-A along fibres/Off-axis matrix } \\
\text { cracking (O) (inclined fibre orientations } \\
\text { at }+45^{\circ} /-45^{\circ} \text { ) }\end{array}$ & Cohesive: $\mathrm{COH} 3 \mathrm{D} 8$ & 3D orthotropic & $\begin{array}{l}\text { QUADS, ENERGY, BK or power } \\
\text { law for mixed modes }\end{array}$ \\
\hline $\begin{array}{l}\text { Type-A transverse to fibres/ Resin-rich } \\
\text { opening failure mode (RO) (bulk } \\
\text { delamination) }\end{array}$ & Cohesive: COH3D6 & 3D orthotropic & $\begin{array}{l}\text { QUADS, ENERGY, BK or power } \\
\text { law for mixed modes }\end{array}$ \\
\hline $\begin{array}{l}\text { Type-B along fibres/ Resin-rich } \\
\text { transverse failure mode (RT) (bulk } \\
\text { delamination) }\end{array}$ & Cohesive: COH3D6 & 3D orthotropic & $\begin{array}{l}\text { QUADS, ENERGY, BK or power } \\
\text { law for mixed modes }\end{array}$ \\
\hline Elastic-plastic deformations (EP) & Solid: C3D6 & $\begin{array}{l}\text { Poisson elasticity } \\
\text { or 3D orthotropic }\end{array}$ & ORIENT, UMAT \\
\hline
\end{tabular}

\subsection{Validation strategy}

In this paper, the predictions of finite element models are compared with the time-lapse X-ray CT loading sequence. Two aspects are compared in this work: (1) a direct comparison of the damage mechanisms in terms of global degradation and (2) a comparison of the modelled stress-strain response versus the experimentally recorded loading data.

\section{Results}

\subsection{Meso-scale damage sequences}

For the meso-scale modelling it is important to realistically capture the damage sequences and fracture processes. Although full-field stress and strain tensors could be plotted showing the fine details of the various stress and strain components, the degradation index (QUADSCRT) is probably more meaningful for tracking the damage sequences. This index indicates damage initiation when it reaches 1 (coloured red in Fig. 9), and thus it reveals the levels of damage in the adjacent regions at the point of local failures.

An example of the $0^{\circ}$ fibre ply model under tension parallel to the z-axis using the Type-A boundary conditions is shown in Fig. 9. Fig. 10 shows the damage sequence after the point of break-through fracture shown in Fig. 9- $d$. It is evident from both these figures that the complete uniaxial failure mode occurs in stages:

1) the localisation of sliding interfaces to debonding (Fig. $9-a, b$ ),

2) matrix cracking (Fig. $9-d$ )

3) fibre fracture (Fig. $9-d$ ) and 
4) further matrix crack opening (Fig. $10-b, c, d$ ).
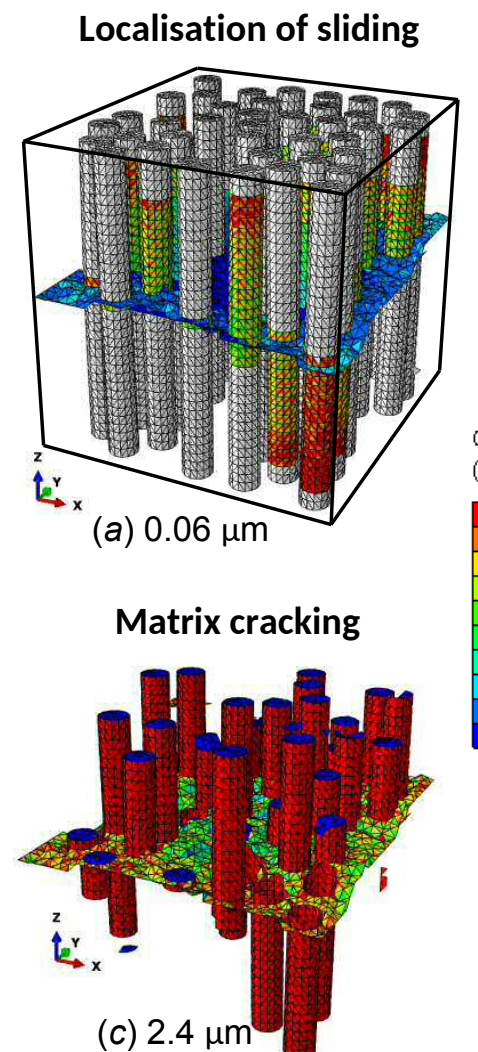

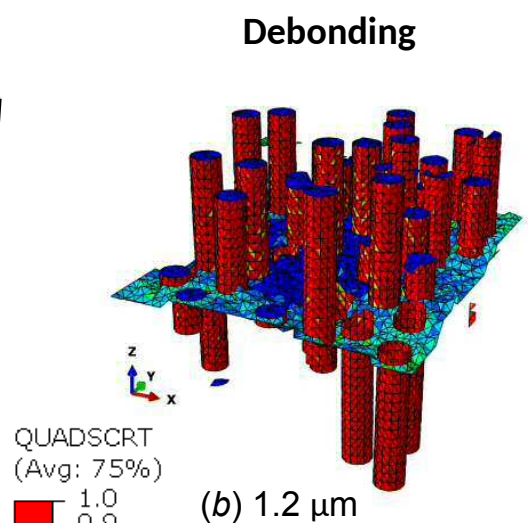

(b) $1.2 \mu \mathrm{m}$

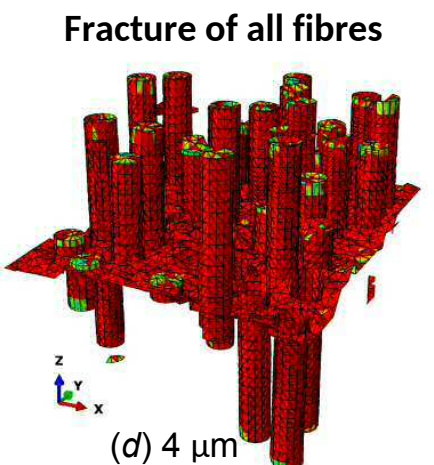

Fig. 9. Plots of the degradation index showing the sequence of damage and crack propagation for the image-based model MeE-8 subjected to type-A tensile loading conditions parallel the fibre-axis ( $z$ ) as a function of elongation. Only those elements that ultimately fail (damage index=1) are shown.

In this particular model, the majority of fibre-matrix debondings are occurring before the breaking failure of fibres. The breaking fibres are also seen as a rapid cluster sequence of individual failures. Typically, in a $0^{\circ}$ meso-scale model with large loading volume areas under tension, this behaviour would be in contrast with several damage observations reported in the literature showing that fibrematrix debonding occurs as a consequence of a fibre failure. However, we believe that further pullout associated debondings can also occur in a realistic ultra-large volume analysis, despite the fact that such a gigantic model simulation has not been analysed here. 

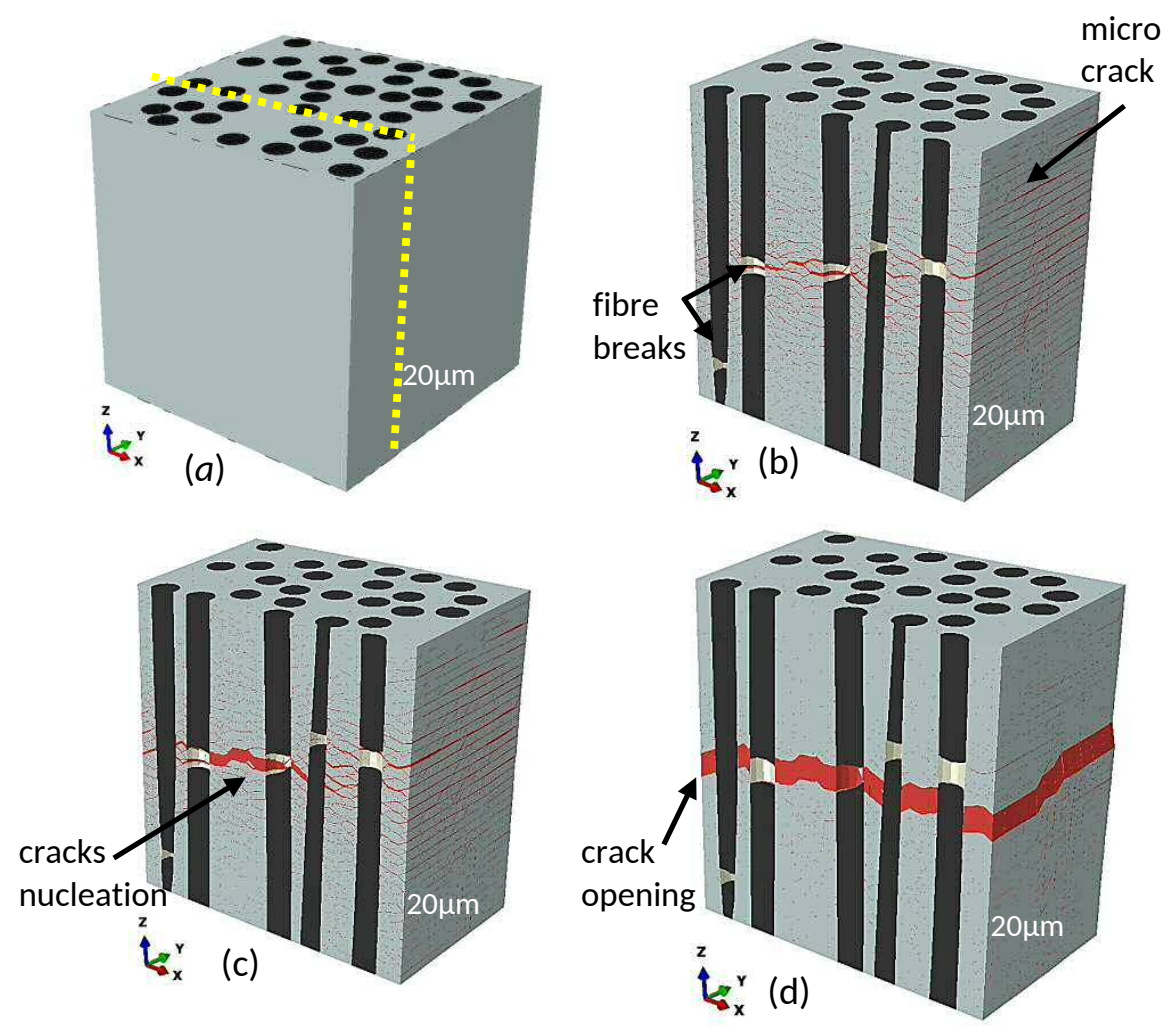

Fig. 10. Sequence of damage and crack propagation after the onset of fibre breaks for a $2 \mathrm{D}$ longitudinal section through the image-based model MeE-8. The model is subjected to type-A tensile loading conditions along the fibre-axis $(z)$ and shows the damages for imposed displacements of b) $5 \mu \mathrm{m}$, c) $5.5 \mu \mathrm{m}$ and d) $6 \mu \mathrm{m}$.

Fig. 11 further shows other typical damage morphology plots corresponding to the complete matrix cracking stage for the $90^{\circ},-45^{\circ}$ and $+45^{\circ}$ fibre orientations respectively. Transverse matrix cracking accompanied by fibre-matrix debonding are the dominant failure mechanisms for loading at $90^{\circ}$ (Fig. 11- $a, c$ ), as well as under shear (Fig. 11-b). Similar morphologies are observed for the $-45^{\circ}$ and $+45^{\circ}$ plies, although the crack surfaces are less macroscopically flat (Fig. 11-d). 

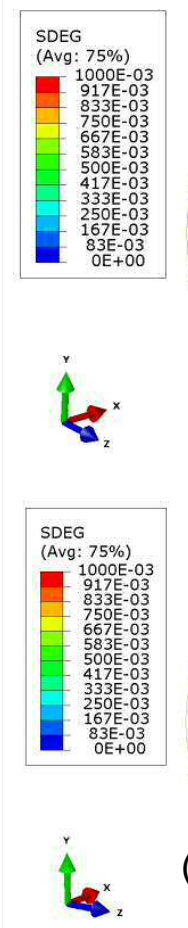

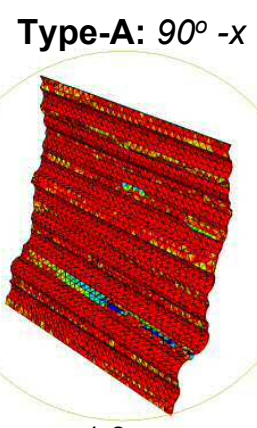

$1.8 \mu \mathrm{m}$

Type-A: $-45^{\circ}-x$

(c)

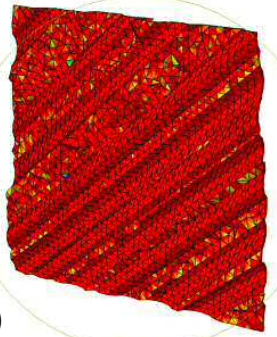

$1.8 \mu \mathrm{m}$

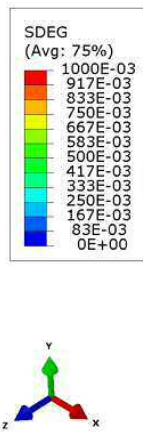

(b)

Type-B: $0^{0}-z$

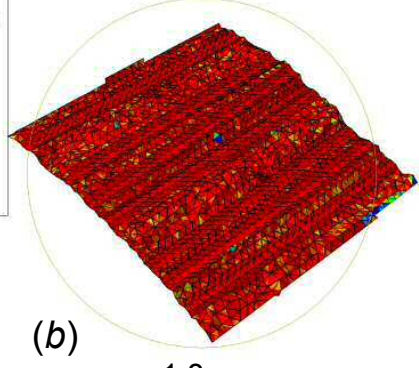

Type-A: $+45^{\circ}-z$

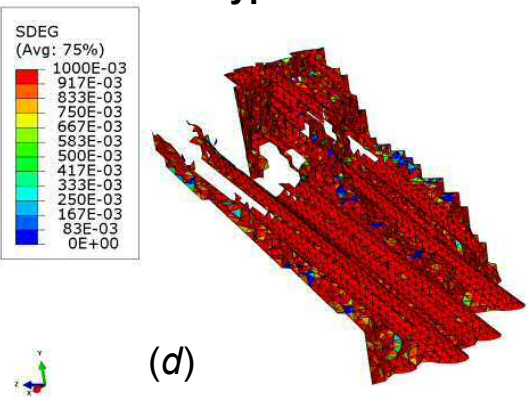

$1.8 \mu \mathrm{m}$

Fig. 11. Fracture surfaces (coloured red) for the image-based models containing for various load cases contain 4 types of fibre orientations.

\subsection{Meso-scale stress-displacement curves}

Fig. 12 and Fig. 13 show a set of stress-displacement curves corresponding to the $-45^{\circ},+45^{\circ}$ and $90^{\circ}$, $0^{\circ}$ fibre ply simulations respectively. Three simulations corresponding to the local extraction axes $\mathrm{x}, \mathrm{y}$ and $z$ are conducted for each set of loading and boundary conditions. In this sense, Type A: 1-3 means that boundary conditions were flipped on all local material orientation axes and simulated in separate numerical models. These simulations were labelled 1 to 3 respectively and so on for the simulation number continuation. The stress displacement curves were then used to extract material constants required for the definition of macro-scale local material models.
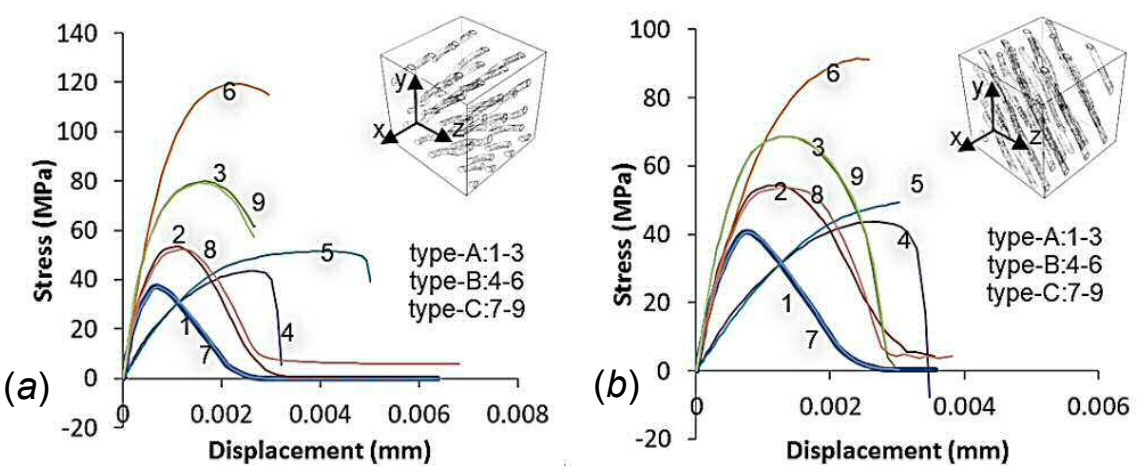

Fig. 12. Stress-displacement curves at the ply level obtained from MeE simulations that contain $a)-45^{\circ}$ and $\left.b\right)+45^{\circ}$ oriented fibres for the various boundary conditions. 

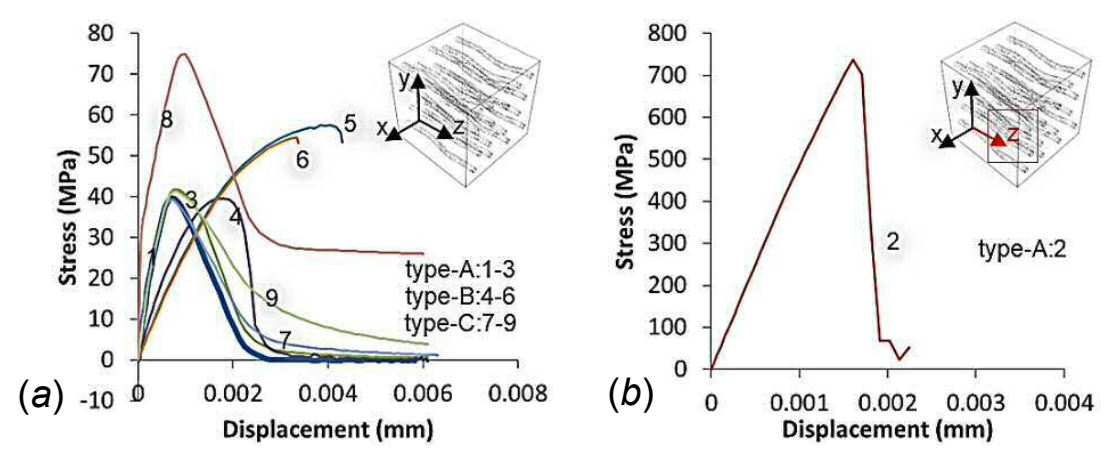

Fig. 13. Stress-displacement curves at the ply level obtained from MeE simulations that contain $90^{\circ}$ oriented fibres for the various boundary conditions (note this set can also be seen as representative to those for the $0^{\circ}$ case but with the axes interchanged).

\subsection{Macro-scale simulation}

This section presents the results of global multiscale modelling of the tensile test-piece. The maximum principal stresses and vertical loading contour stresses along direction $\mathrm{Y}$ are shown in Fig. 14 and Fig. 15 respectively. The plots correspond to different straining steps during the global simulation. Because the maximum principal stress is oriented in different directions in different locations, but also as different damage mechanisms kick in, they highlight important failure mechanisms and reveal how the load distribution and redistribution occurs within the global model upon the use of the orientation sub-routine. The model predicts that the inclined fibre plies $\left(-45^{\circ}\right.$ and $+45^{\circ}$ ) fail before the transverse fibre plies oriented at $90^{\circ}$. The delamination of the so-called 'resinrich' layers also begins before the failure stress is reached in the inclined fibre plies (i.e. below $14 \mu \mathrm{m}$ overall crosshead extension in Fig. 14-a). The delamination was also evident in the overstressed single element rows appearing in Fig. 14-c, while for the two $0^{\circ}$ plies located nearest to the two notches a significant bear fraction of the stress was observed. 


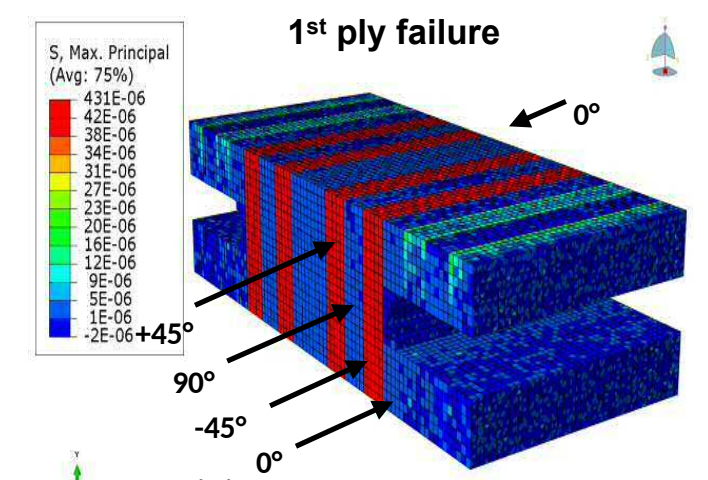

(a) $14 \mu \mathrm{m}$

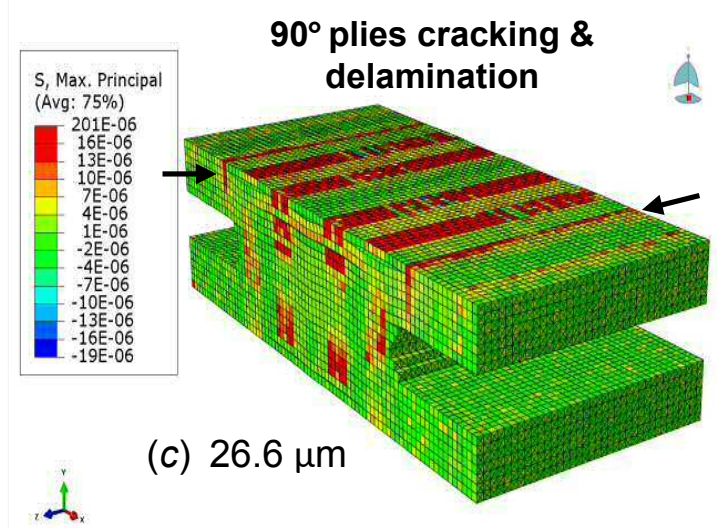

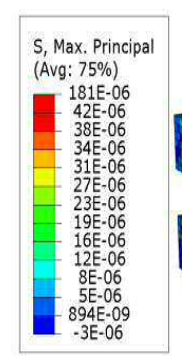

$+/-45^{\circ}$ plies cracking

1

L.

(b) $18.2 \mu \mathrm{m}$

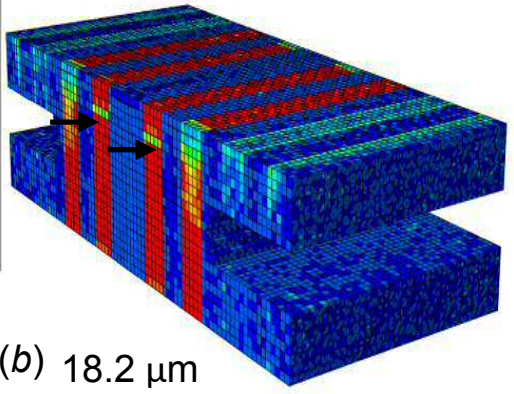

$0^{\circ}$ plies final cracking

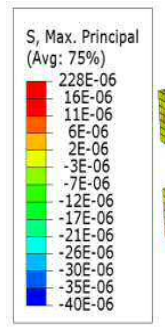

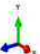

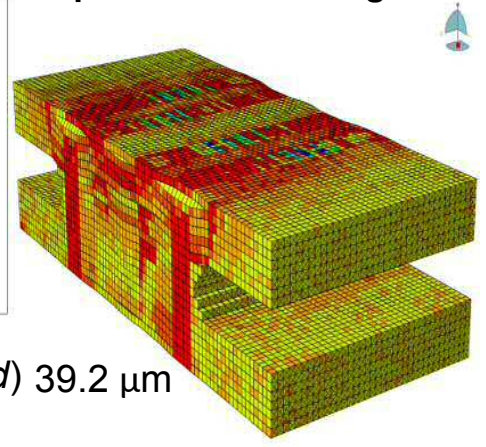

Fig. 14. Principal stress contours in the multiscale model with increased straining (displacement) with the new major damage mechanisms identified at each approximate stage.

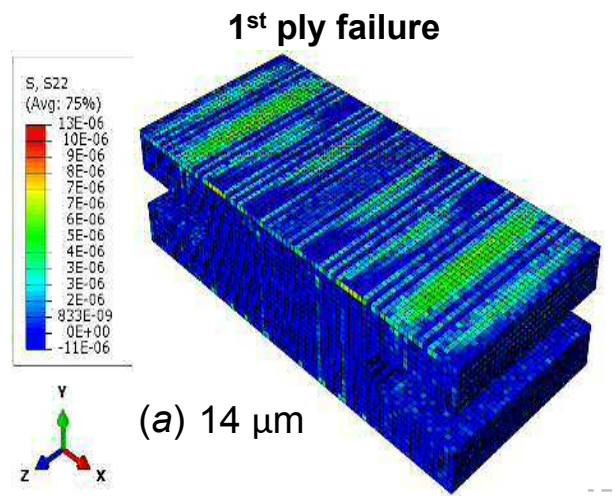

$90^{\circ}$ plies cracking $\&$ delamination

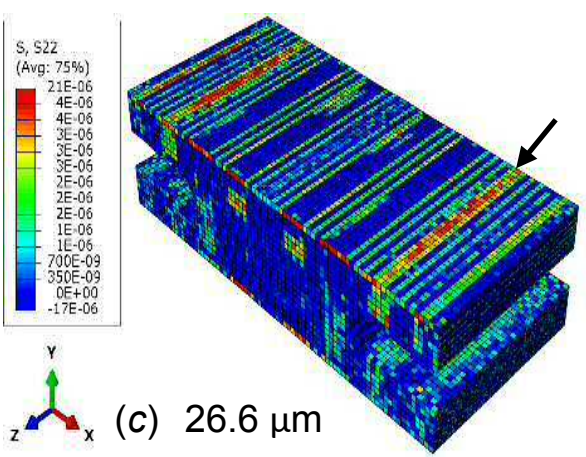

\section{$+/-45^{\circ}$ plies cracking}
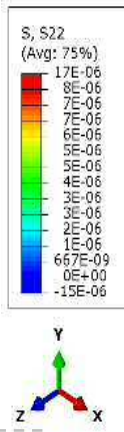

(b) $18.2 \mu \mathrm{m}$

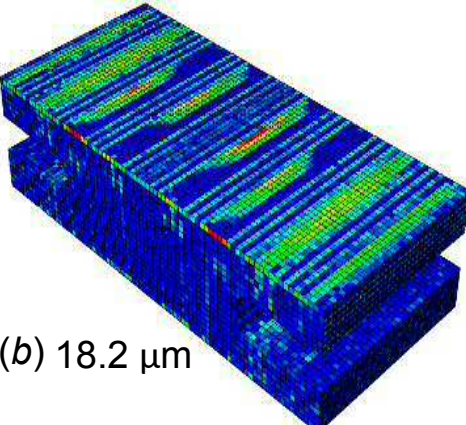

$0^{\circ}$ plies final cracking

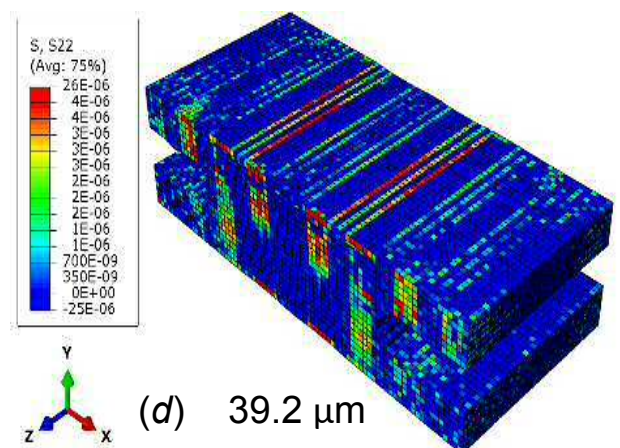

Fig. 15. Stress contours along vertical loading direction $Y$ in multiscale model at overall applied displacements corresponding to Fig. 14. 


\subsection{Validation}

Fig. 16 shows a visual comparison between the multiscale model and the failure observed in practice by the X-ray CT. The fracture surface in the model is based on the regions where the damage index exceeds 0 .9. This shows very good agreement with the morphology and level of damage observed by $\mathrm{X}$-ray $\mathrm{CT}$, confirming that the complex global failure morphology can be captured using the multiscale model in this study.
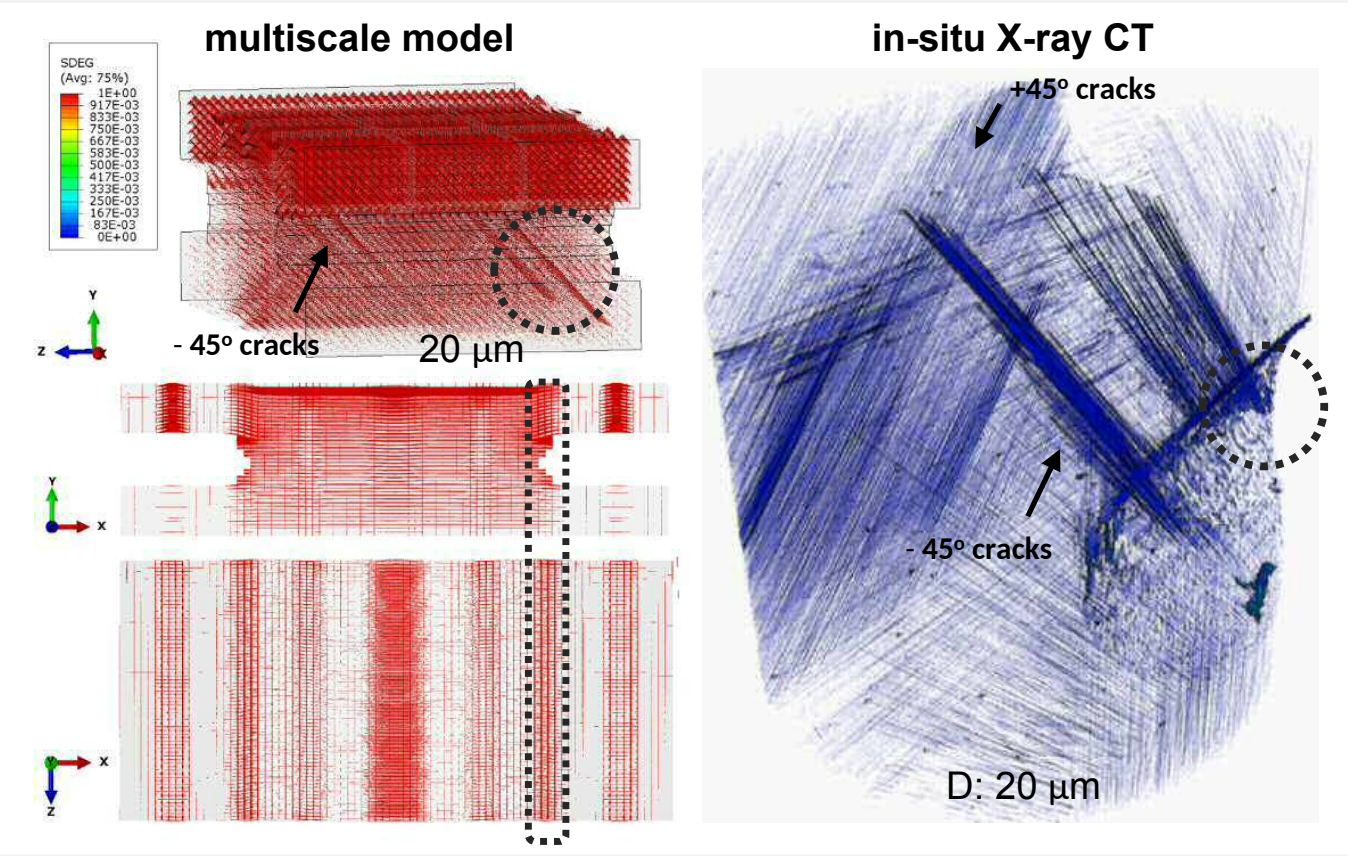

Fig. 16. Comparison of damage and crack patterns in the double notched test-piece simulated by the multiscale model (left) and recorded by X-ray CT (right).

Fig. 17 compares the actual and predicted stress-displacement curves. It appears that at loading point $A$, the $90^{\circ}$ ply matrix cracking and $-1+45^{\circ}$ to $90^{\circ}$ delamination were already initiated at approximately $120 \mathrm{~N}$ applied force. These are followed by extensive splitting and cracking up to point $B$, when only a few local fibre breakage occurs. Point $C$ follows a similar loading stiffness although the maximum load that could be reached upon the reloading/relaxation was about $15 \%$ less than previous in-situ loading at step $B$. Points $D$ and $E$ show considerably modified loading stiffnesses that could be associated with further damage and local micro- and meso-scale failures producing different relaxations during the in-situ scanning (see vertical unloading lines at points $D$ and $E$ in Fig. 17).

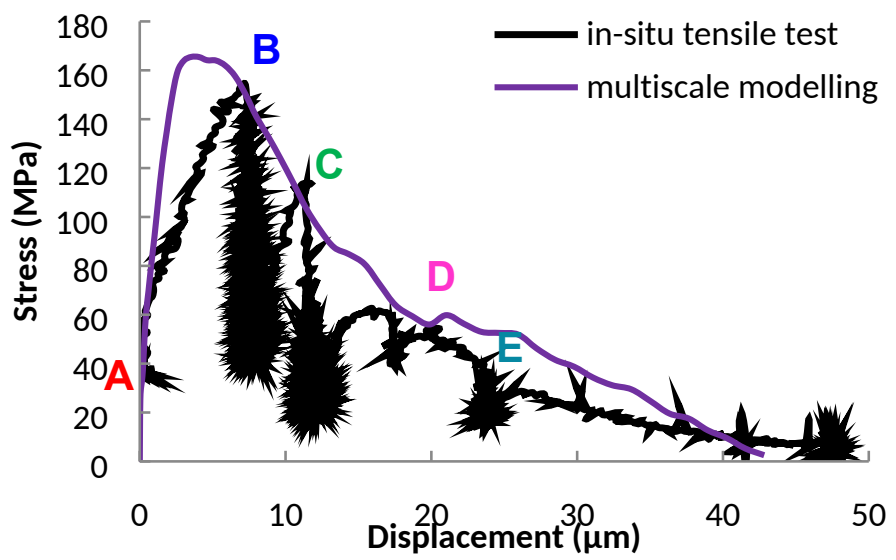

Fig. 17. Comparison of stress-displacement curves of FE multiscale model (purple line) and the actual in-situ tensile experimental test (black). Note that points B, C, D and E here are arbitrary points of the X-ray CT scanning steps along the complete loading process and they do not replicate to FE modelling results. 
Although the peak load is satisfactorily predicted, the slope of the curve from A to B is highly overestimated. In addition, the subsequent load drops and peaks are not described by the multiscale model due to difficulties in fully integrating the overall in-situ loading sequence.

In general, the complexity of the failure mechanism in multidirectional fibre reinforced composites involves a combination of micro-scale matrix cracking, fibre fractures and delamination of resin-rich layers. Although, some local fibre breaks have potentially initiated during the mechanical loading, complete fibre ply failure was not captured during the in-situ tensile test due to several local failures, load relaxations and difficulties associated with mapping the field of view in the deformed region of interest. However, one of the main advantages of carrying the detailed damage and fracture modelling with better loading programme control at meso-scale is that the fibre breaking and delamination types of failures can be inspected in greater details to inform both, the meso and macro-scale modelling. The macro-scale simulation on the other hand also provides a total fracture energy release that depends on the meso-scale responses in this case. In future, this fracture energy could be estimated as a total quantity in the image-based models or could even be assessed as a cumulative function of all damage created during several in-situ loading steps.

\subsection{Limitations}

Random properties had to be used throughout the modelling, partly because of the limited X-ray CT volume information, and partly due to numerical reconstruction and FE integration challenges as for a complete grid partitioning and expansion of a fully integrative modelling approach. Instead, the random variation was only simulated here by mimicking existing inputs via a random number generation using Matlab software. A total variation of $10 \%$ was used. This variation percentage is selected based on visual observations and previous 2D studies [48, 54], but also because of a lack of detailed studies on how to quantify such variations, particularly for any related aerospace grade CFRP samples, which was previously identified. In future, it would be preferable to characterise all the locations experimentally and inform both material scales with more accurate input data or even merge the multiple scales as a complete fused image-based model.

In the case of failure criteria at macro-scale, it was previously recommended that the fracture release energy of all macro-CIEs should be kept to less than the non-linear energy taken from micro-/ mesoscale analyses [55]. The evaluation of the complete softening relations was first undertaken in our study. This evaluation, although necessary for the macro-scale approach using the zero-thickness cohesive interface and solid elements, has led to a reasonable agreement of the load versus displacement curve. Typically, when using hierarchical modelling approaches such as following a precise delineation of the MeE responses into elastic, pseudo-elastic and then softening curve according to quasi-brittle damage mechanics behaviour, the geometrical separation of scales remains important for the estimation of local fracture energies. The relatively coarse mesh size element used in the global macro-scale model could not capture the micro-cracking entities very accurately, and hence, affecting less on the initial load-displacement and dwells. Further sensitivity studies such as using different separation of scales, the aspect ratios between the meso and macro length scales, or even when using different meta transfer models are further necessary.

\section{Summary and conclusions}

In this paper, a multiscale image-based hierarchical approach is proposed capable of capturing the tensile failure behaviour of multidirectional composite laminate test-pieces. This has the potential of fully integrating the material knowledge, while assuming that manufacturing defects can also be linked based on their closest length scales. The modelling of damage and fracture was based on the multi-phase cohesive interface elements crack model approach developed in [48].

The following conclusions may be drawn from the study: 
(i) more realistic 3D simulations based on reconstructed X-ray CT images can now be employed for more accurate and reliable damage and fracture analyses.

(ii) simulations of meso-scale elements provide extensive details such as micro-elasticity, pseudo-plasticity (nonlinear curves taken from meso-scale simulations), fracture energy and multi-phase crack surfaces (matrix, fibres and interfaces).

(iii) using cohesive interface elements, the damage sequence and complete morphology can be more realistically captured than the overall stress-strain response and failure envelope predicted.

(iv) manufacturing heterogeneities such as the 3D fibre waviness/misalignments and fibre splits can be easily integrated within the model, being also in line with the 3-phase cohesive interface crack model that was developed.

(v) at the meso-scale, material anisotropy behaviour that must be included, could be captured sufficiently accurate by a set of comprehensive boundary condition models.

(vi) further imaging and numerical integration steps are essential in preserving the exact material fibre topology data and in time can improve the design reliability and suitability for meeting certain specifications and structural performances.

(vii) the proposed multiscale modelling method informed by in-situ X-ray CT tests will eventually unlock a new reverse engineering technology, that could potentially be taken into consideration before the selection of an optimum structural design.

\section{Acknowledgements}

This study was funded by a U.S. Air Force EOARD grant no. FA8655-12-1-2100 and EPSRC grant no. EP/J019763/1 at University of Manchester. The X-ray CT experiments were conducted at the DiamondManchester Branchline I-13-2 under experiment session MT10456-2 at the national synchrotron Diamond Light Source in Oxfordshire, United Kingdom. The help and assistance Mr. Razvan Vasiliu and Mr. Alex Borsciov during the experimentation are greatly appreciated. P.J.W. is grateful to the European Research Council for the funding under CORREL-CT [grant no. 695638].

\section{References}

[1] Hill, R., Elastic properties of reinforced solids: Some theoretical principles. Journal of the Mechanics and Physics of Solids, 1963. 11(5): p. 357-372.

[2] EOARD, U.S. Air Force - $h$ ttp://www.nrl.navy.mil/accomplishments/materials/fracture-mechanics 2016.

[3] NRL, U.S. Naval Reseach Laboratory - http://www.nrl.navy.mil/accomplishments/materials/fracturemechanics 2016.

[4] Needleman, A., Some Issues in Cohesive Surface Modeling. Procedia IUTAM, 2014. 10: p. 221-246.

[5] de Borst, R., Challenges in computational materials science: Multiple scales, multi-physics and evolving discontinuities. Computational Materials Science, 2008. 43(1): p. 1-15.

[6] Fish, J., Multiscale Modeling and Simulation of Composite Materials and Structures

Multiscale Methods in Computational Mechanics, R. de Borst and E. Ramm, Editors. 2011, Springer Berlin / Heidelberg. p. 215-231.

[7] Gitman, I.M., H. Askes, and L.J. Sluys, Representative volume: Existence and size determination. Engineering Fracture Mechanics, 2007. 74(16): p. 2518-2534.

[8] Trias, D., et al., Determination of the critical size of a statistical representative volume element (SRVE) for carbon reinforced polymers. Acta Materialia, 2006. 54(13): p. 3471-3484.

[9] González, C. and J. Llorca, Multiscale modeling of fracture in fiber-reinforced composites. Acta Materialia, 2006. 54(16): p. 4171-4181.

[10] Sakata, S., F. Ashida, and K. Enya, A Microscopic failure probability analysis of a unidirectional fiber reinforced composite material via a multiscale stochastic stress analysis for a microscopic random variation of an elastic property. Computational Materials Science, 2012. 62(0): p. 35-46. 
[11] Novák, J., A. Kučerová, and J. Zeman, Compressing random microstructures via stochastic Wang tilings. Physical Review E, 2012. 86(4): p. 040104.

[12] Guilleminot, J., et al., Theoretical framework and experimental procedure for modelling mesoscopic volume fraction stochastic fluctuations in fiber reinforced composites. International Journal of Solids and Structures, 2008. 45(21): p. 5567-5583.

[13] Unger, J.F., An FE2-X1 approach for multiscale localization phenomena. Journal of the Mechanics and Physics of Solids, 2013. 61(4): p. 928-948.

[14] Li, S. and S. Ghosh, Extended Voronoi cell finite element model for multiple cohesive crack propagation in brittle materials. International Journal for Numerical Methods in Engineering, 2006. 65(7): p. 10281067.

[15] Ghosh, S., Adaptive Concurrent Multi-Level Model for Multiscale Analysis of Composite Materials Including Damage. 2008, Springer US. p. 83-163.

[16] Cid Alfaro, M.V., A.S.J. Suiker, and R. de Borst, Transverse Failure Behavior of Fibre-epoxy Systems. Journal of Composite Materials, 2010.

[17] Cid Alfaro, M.V., et al., Numerical homogenization of cracking processes in thin fibre-epoxy layers. European Journal of Mechanics - A/Solids, 2010. 29(2): p. 119-131.

[18] Wang, H.W., et al., Application of extended finite element method in damage progress simulation of fiber reinforced composites. Materials \& Design, 2014. 55(0): p. 191-196.

[19] Mishnaevsky Jr, L. and P. Brøndsted, Micromechanisms of damage in unidirectional fiber reinforced composites: 3D computational analysis. Composites Science and Technology, 2009. 69(7-8): p. 10361044.

[20] Fish, J. and K. Shek, Finite deformation plasticity for composite structures: Computational models and adaptive strategies. Computer Methods in Applied Mechanics and Engineering, 1999. 172(1-4): p. 145174.

[21] Singh, H., M. Gupta, and P. Mahajan, Reduced order multiscale modeling of fiber reinforced polymer composites including plasticity and damage. Mechanics of Materials, 2017. 111: p. 35-56.

[22] Soni, G., et al., Modelling matrix damage and fibre-matrix interfacial decohesion in composite laminates via a multi-fibre multi-layer representative volume element (M2RVE). International Journal of Solids and Structures, 2014. 51(2): p. 449-461.

[23] Soni, G., et al., Study of localized damage in composite laminates using micro-macro approach. Composite Structures, 2014. 113: p. 1-11.

[24] Requena, G., et al., 3D-Quantification of the distribution of continuous fibres in unidirectionally reinforced composites. Composites Part A: Applied Science and Manufacturing, 2009. 40(2): p. 152-163.

[25] Viguié, J., et al., Finding fibres and their contacts within 3D images of disordered fibrous media. Composites Science and Technology, 2013. 89(0): p. 202-210.

[26] Yang, H. and W.B. Lindquist. Three-dimensional image analysis of fibrous materials. 2000.

[27] Emerson, M.J., et al., Quantifying fibre reorientation during axial compression of a composite through time-lapse X-ray imaging and individual fibre tracking. Composites Science and Technology, 2018. 168: p. 47-54.

[28] Withers, P.J., Fracture mechanics by three-dimensional crack-tip synchrotron X-ray microscopy. Philos Trans A Math Phys Eng Sci, 2015. 373(2036).

[29] Withers, P.J., et al., Evolution of crack-bridging and crack-tip driving force during the growth of a fatigue crack in a Ti/SiC composite. Proceedings of the Royal Society A: Mathematical, Physical and Engineering Sciences, 2012. 468(2145): p. 2722-2743.

[30] Garcea, S.C., et al., Fatigue micromechanism characterisation in carbon fibre reinforced polymers using synchrotron radiation computed tomography. Composites Science and Technology, 2014. 99: p. 23-30.

[31] Scott, A.E., et al., Damage accumulation in a carbon/epoxy composite: Comparison between a multiscale model and computed tomography experimental results. Composites Part A: Applied Science and Manufacturing, 2012. 43(9): p. 1514-1522.

[32] Garcea, S.C., Y. Wang, and P.J. Withers, X-ray computed tomography of polymer composites. Composites Science and Technology, 2018. 156: p. 305-319.

[33] O'Masta, M.R., V.S. Deshpande, and H.N.G. Wadley, Defect controlled transverse compressive strength of polyethylene fiber laminates. International Journal of Solids and Structures, 2015. 52(0): p. 130-149.

[34] Wang, Y., et al., X-ray computed tomography study of kink bands in unidirectional composites. Composite Structures, 2017. 160: p. 917-924. 
[35] Czabaj, M.W., M.L. Riccio, and W.W. Whitacre, Numerical reconstruction of graphite/epoxy composite microstructure based on sub-micron resolution X-ray computed tomography. Composites Science and Technology, 2014. 105(0): p. 174-182.

[36] Sencu, R.M., et al., Generation of micro-scale finite element models from synchrotron X-ray CT images for multidirectional carbon fibre reinforced composites. Composites Part A: Applied Science and Manufacturing, 2016. 91: p. 85-95.

[37] Needleman, A., Computational mechanics at the mesoscale. Acta Materialia, 2000. 48(1): p. 105-124.

[38] Needleman, A., An analysis of decohesion along an imperfect interface. International Journal of Fracture, 1990. 42(1): p. 21-40.

[39] Rosenfield, A.R. and M.F. Kanninen, The fracture mechanics of glassy polymers. Journal of Macromolecular Science, Part B, 2006. 7(4): p. 609-631.

[40] Rybicki, E.F. and M.F. Kanninen, The Effect of Different Behavior in Tension than in Compression on the Mechanical Response of Polymeric Materials, in Deformation and Fracture of High Polymers, H.H. Kausch, J.A. Hassell, and R.I. Jaffee, Editors. 1973, Springer US: Boston, MA. p. 417-427.

[41] Soutis, C. and P.T. Curtis, A method for predicting the fracture toughness of CFRP laminates failing by fibre microbuckling. Composites: Part A 31 (2000) 733-740, 1999.

[42] Rudraraju, S., et al., Predictions of crack propagation using a variational multiscale approach and its application to fracture in laminated fiber reinforced composites. Composite Structures, 2012(0).

[43] Song, S.J. and A.M. Waas, Energy-based mechanical model for mixed mode failure of laminated composites. AIAA Journal, 01/11/1995. 33(4): p. 739-745.

[44] Rudraraju, S.S., et al., In-plane fracture of laminated fiber reinforced composites with varying fracture resistance: Experimental observations and numerical crack propagation simulations. International Journal of Solids and Structures, 2010. 47(7-8): p. 901-911.

[45] Rudraraju, S.S., et al., On the Theory and Numerical Simulation of Cohesive Crack Propagation With Application to Fiber-Reinforced Composites. 2013(NASA/TP-2013-217431).

[46] Oliver, J., A.E. Huespe, and P.J. Sánchez, A comparative study on finite elements for capturing strong discontinuities: E-FEM vs X-FEM. Computer Methods in Applied Mechanics and Engineering, 2006. 195(37-40): p. 4732-4752.

[47] Sencu, R.M., Z. Yang, and Y.C. Wang, An adaptive stochastic multi-scale method for cohesive fracture modelling of quasi-brittle heterogeneous materials under uniaxial tension. Engineering Fracture Mechanics, 2016. 163: p. 499-522.

[48] Sencu, R.M., Multiscale stochastic fracture mechanics of composites informed by in-situ X-ray CT tests, in School of Mechanical, Aerospace and Civil Engineering2016, University of Manchester: University of Manchester. p. 218.

[49] Basham, M., et al., Data Analysis WorkbeNch (DAWN). Journal of Synchrotron Radiation, 2015. 22(3): p. 853-858.

[50] FEl/Avizo, Software Version Avizo 8 Fire - Educational License at University of Manchester.

[51] Sencu, R.M., Z. Yang, and Y.C. Wang, From micro to macro: simulating crack propagation in carbon fibre composites, in Structural Integrity and Durability of Advanced Composites. 2015, Elsevier.

[52] Simulia/Abaqus, - Abaqus theory manual. Online version 6.12.

[53] Simulia/Abaqus, - Abaqus user subroutines reference manual. Online version 6.12.

[54] Sencu, R.M., Z. Yang, and Y.C. Wang, A multiscale stochastic fracture modelling calibration using Monte Carlo simulations. Proceedings of the 22nd UK Conference of the Association for Computational Mechanics in Engineering, 2014(2014): p. 105-108.

[55] Lopes, C.S., et al., Physically-sound simulation of low-velocity impact on fiber reinforced laminates. International Journal of Impact Engineering, 2015. 